\title{
Detailed Assessment of Global Transport-Energy Models' Structures and Projections
}

\author{
Sonia Yeh ${ }^{1,2}$, Gouri Shankar Mishra ${ }^{1,3}$, Lew Fulton ${ }^{1}$, Page Kyle ${ }^{4}$, David L. McCollum ${ }^{5,6}$, Joshua \\ Miller $^{7}$, Pierpaolo Cazzola ${ }^{8}$, Jacob Teter ${ }^{8}$ \\ ${ }^{1}$ Institute of Transportation Studies, University of California, Davis, USA. \\ ${ }^{2}$ Department of Energy and Environment, Chalmers University of Technology, Sweden \\ ${ }^{3}$ Precourt Energy Efficiency Center, Stanford University, USA \\ ${ }^{4}$ Joint Global Change Research Institute, Pacific Northwest National Laboratory, USA. \\ ${ }^{5}$ Energy Program, International Institute for Applied Systems Analysis, Austria. \\ ${ }^{6}$ Howard H. Baker Jr. Center for Public Policy, University of Tennessee, USA. \\ ${ }^{7}$ International Council on Clean Transportation, USA. \\ ${ }^{8}$ International Energy Agency, France
}

\begin{abstract}
This paper focuses on comparing the frameworks and projections from four global transportation models with considerable technology details. We analyze and compare the modeling frameworks, underlying data, assumptions, intermediate parameters, and projections to identify the sources of divergence or consistency, as well as key knowledge gaps. We find that there are significant differences in the base-year data and key parameters for future projections, especially for developing countries. These include passenger and freight activity, mode shares, vehicle ownership rates, and even energy consumption by mode, particularly for shipping, aviation and trucking. This may be due in part to a lack of previous efforts to do such consistency-checking and "bench-marking." We find that the four models differ in terms of the relative roles of various mitigation strategies to achieve a $2{ }^{\circ} \mathrm{C} / 450 \mathrm{ppm}$ target: the economics-based integrated assessment models favor the use of low carbon fuels as the primary mitigation option followed by efficiency improvements, whereas transport-only and expert-based models favor efficiency improvements of vehicles followed by mode shifts. We offer recommendations for future modeling improvements focusing on (1) reducing data gaps; (2) translating the findings from this study into relevant policy implications such as gaps of current policy goals, additional policy targets needed, regional vs. global reductions, etc.; (3) modeling strata of demographic groups to improve understanding of vehicle ownership levels, travel behavior, and urban vs. rural considerations; and (4) conducting coordinated efforts in aligning historical data, and comparing input assumptions and results of policy analysis and modeling insights.
\end{abstract}

Keywords: transportation scenarios, transportation behaviors, energy use, climate mitigation, GHG emissions, transportation demand, model comparison. 


\section{Introduction}

Transportation accounts for a significant portion of global fossil fuel use and greenhouse gas (GHG) emissions (IPCC 2014b). Therefore, reductions in transportation-sector emissions will play an important role in any comprehensive carbon reduction strategy. Abatement in the sector will be multifaceted, and may include emissions reductions through increased efficiency of vehicle fleets, lower carbon intensity (CI) of fuels, and/or reduced demand for vehicle-kilometers traveled (Creutzig et al. 2015). Several recent studies comparing global transportation models have looked into the growth trajectories of transportation demand and potentials of mitigation options to meet climate mitigation goals (Edelenbosch, Luderer, et al. 2016, Pietzcker et al. 2014, Girod et al. 2013). These modeling comparison studies generally focus on projections of fuel use, GHG emissions and technology and fuel mixes in business-as-usual (BAU) and in GHG abatement scenarios, and are for the most part based on results of whole-systems and integrated assessment models (IAMs).

This paper presents the results of a model comparison effort called iTEM (International Transportation Energy Modeling). It focuses on comparing the frameworks and scenario projections from four major global transportation models that have a high degree of technology details compared with most major IAMs, allowing a deeper level of analysis than has been performed in the previous literature to date. Our goal is to conduct a detailed comparison of modeling framework, underlying data, assumptions, intermediate parameters, and projections, to gain a better knowledge of the sources of divergence or consistency. We also aim to identify potential knowledge gaps in data, new model methods and transportation topics.

\section{Comparison of Model Structure}

The four models compared in this work include:

- Global Change Assessment Model (GCAM) by Pacific Northwest National Laboratory (PNNL) with modification for the transportation sector by the Institute of Transportation Studies (ITS), University of California, Davis,

- MESSAGE-Transport (Model for Energy Supply Strategy Alternatives and their General Environmental Impact) by the International Institute for Applied Systems Analysis (IIASA),

- Mobility Model (MoMo) by the International Energy Agency (IEA), and

- Roadmap by the International Council on Clean Transportation (ICCT).

The four models differ in terms of scope and model structure. GCAM and MESSAGE cover all sectors of the energy system, including linkages with global land use, energy/economic, and/or climate systems, whereas MoMo and Roadmap cover the global transportation sector only. GCAM and MESSAGE tend to rely on cross-sectoral endogenous functions to project future development, whereas MoMo and Roadmap rely more heavily on expert judgment and detailed, country-specific research and expertise. Yet, owing to these differences, the models are highly complementary and in some cases can be used jointly to answer questions that no single model can address in isolation.

In this section we provide a brief overview of each of the model, and compare the model structure and key mechanisms that drive the major differences in these models.

\subsection{Global transportation models}

The Global Change Assessment Model (GCAM) is a global (multi-region, multi-sector) dynamic-recursive partial equilibrium model with technology-rich representations of the economy, energy sector, land use and water (Kim et al. 2016) linked to a climate model. The model has participated in many international modeling comparison efforts involving integrated 
assessment models, including those in climate change scenarios (Fawcett et al. 2015), natural gas (McJeon et al. 2014), land use (Di Vittorio et al. 2014), and transportation (Girod et al. 2013). The new transportation module of GCAM was developed in a collaborative effort between PNNL (Kyle and Kim. 2011) and ITS at the University of California, Davis (Mishra et al. 2013).

The MESSAGE model is a global (multi-region, multi-sector) systems engineering, intertemporal optimization model that has rich technological detail, particularly on the supply side of the energy system (Riahi et al. 2012). MESSAGE is linked to other models for studying impacts of the energy system on land use and forestry, macro-economics, air pollution, and climate change. More recently a significant amount of technology detail has also been added to the transportation sector of MESSAGE (McCollum et al. 2016). The model has also participated in many international modeling comparison efforts involving integrated assessment models, including van der Zwaan et al. (2013), Tavoni et al. (2015), McJeon et al. (2014), (IPCC 2014a); recently the model is also part of a model comparison focusing on transportation (see also (Edelenbosch, McCollum, et al. 2016)).

The Mobility Model (MoMo) (Fulton, Cazzola, and Cuenot 2009) is a "stand alone" transportation-only model that interacts with IEA's annual Energy Technology Perspectives (ETP) TIMES-based optimization modeling system. MoMo uses a manually iterative process to achieve consistency in energy use and GHG emissions with the ETP scenarios. The 2013 version of MoMo and the scenarios run for ETP 2014 were evaluated in the iTEM model comparison. MoMo tracks transportation activity, energy use, GHG and local pollutant emissions, material use and infrastructure. The model allows the user to create "what-if" scenarios to explore the impacts of various technological, economic, demographic, and policy trends. The calculation of final energy consumption and emissions performed in MoMo is based on the ASIF methodology (Schipper, Saenger, and Sudardshan 2011) that decomposes GHG emissions into the multiplication of four major components: activity (passenger-km or tonne-km for freight), mode shares ( $\%$ of total passenger or tonne-km carried by each mode), fuel intensity of each mode (energy use per passenger (or tonne-) km using fuel or energy source), and carbon content of each fuel used in a particular mode.

The Roadmap model has been developed for the purpose of estimating current and future wellto-wheel emissions and energy consumption by the transportation sector under different policy scenarios (Façanha, Blumberg, and Miller 2012). The model was built using the best available data from public sources and in-country partners, with much of the data for aggregate (multicountry) regions coming from the IEA's MoMo model. Therefore it is structurally similar to the MoMo model. The model was developed to assess transportation systems in the top eleven vehicle markets and in five aggregate regions, enabling global analyses that are based on up-todate policy information and take into account administrative and technical considerations of implementing new policies.

\subsection{Model system boundary, resolution, and structure}

The four models vary in structure, scope, and the variables included in calculations and projections. The transportation sectors of GCAM and MESSAGE are both part of larger, multisector IAMs whereas MoMo and Roadmap are "stand-alone" transportation models, with no endogenous feedback from sectors outside the transportation system to changes in transportation sector assumptions or projections (such as energy use impact on energy prices). As mentioned earlier, however, MoMo outputs are iterated with IEA's ETP scenarios exogenously to achieve consistency in energy use and GHG emissions with global economy-wide ETP scenarios. On the other hand, MoMo and Roadmap tend to have more detailed representations of the transportation 
sector, such as vehicle characteristics, near-term policy goals and implementation, and detailed tracking of vehicle pollutant emissions as a function of vehicle emission control levels and utilization. Table S1 in the Supporting Information (SI) provides a basic comparison of the models' system boundary, resolution, and structure.

\subsection{Projections of service demand, vehicles sales and fuel uses}

Across the four models, population and income (GDP) are the exogenous drivers of passenger service demand in passenger kilometers travelled, PKT (GCAM, MESSAGE, Roadmap) and new vehicle demand (MoMo), as shown in Table 1 and Figure 1. In GCAM and MESSAGE, the passenger service demands by mode are estimated endogenously based on the total travel costs (monetary cost per passenger kilometer travelled, \$/PKT) by mode, fuel, technology, and time cost of travel that is a function of the average hourly wage rate of the employed population, mode-specific value of travel time (VTT), and travel speed). In MoMo, vehicle and 2-wheeler travel demands are estimated based on private vehicle ownership rates that are modeled with Gompertz curves as a function of per-capita GDP, while air travel activity is projected based on historical trends. In Roadmap, PKT is projected based on exogenous changes in GDP, population, and fuel prices. Freight service demand is based on simple functions of population, GDP, and fuel prices (except MoMo) in these models.

The competition between vehicle technologies, including alternative fuel vehicles, is estimated differently by each model (Table S3). In GCAM, it is based on a nested-logit function where the share of technology/mode is determined endogenously based on the average levelized costs of service of each technology/mode in \$/PKT (Mishra et al. 2013, Clarke and Edmonds 1993). Alternatively, technologies are selected based on least-cost optimization of the discounted net present cost of each technology in MESSAGE, subject to constraints on annual sales growth rate and vehicle stock turnover, among others (McCollum et al. 2013). In contrast, technologies are chosen based on expert judgment and what-if analysis in both MoMo and Roadmap. While the rate of efficiency improvement of each represented vehicle technology is exogenous in all four models, the average improvement in energy intensity for modes or classes of technology is endogenous in all four models (Table S4 and Table 1). Table S3 describes the level of detail used to characterize different modes and sectors in the models, and how vehicle stocks, efficiency (Table S4) and fuel demands are determined in these models.

Modeling transportation energy use in these models is either done by estimating how far people travel and what mode of transportation they choose, or by estimating how many vehicles there are and how far each one travels. These are complementary approaches, and in principle they should both lead to similar answers, given a consistent set of assumptions. The former approach, used in "service demand" models, can be more intuitive and appropriate when one wants to model societal shifts in modes of transportation, either in emerging economies as they develop or in developed economies as they decarbonize (Schäfer et al. 2009, Schäfer and Victor 2000); but collecting reliable and consistent data on service demand (including passenger travel demand in PKT, and freight demand in ton-kilometers travelled, TKT, across all modes of transportation) is quite challenging particularly for developing countries. In contrast, vehicle stock models rely upon readily-available vehicle sales data, but are less well suited for projecting future-state, whatif scenarios (particularly in estimating modal shift behaviors) and thus require special attention by experts. On the other hand, the later approach is more responsive to non-cost based policy or social changes that lead to mode shifts or demand reductions. Figure 1 compares the service demand model (GCAM, MESSAGE, and Roadmap) with the car stock (MoMo) model. The figure shows the basic logic, in the form of flow charts, of the four models, illustrating the 
exogeneity vs. endogeneity of variables, and their general connectedness. Table S2 provides a high level comparison of endogeneity/exogeneity of key model drivers and parameters.

\section{$2.4 \quad \mathrm{CO}_{2}$ emission accounting}

The four models have different system boundaries for $\mathrm{CO}_{2}$ emission accounting, with implications for how these emissions are accounted for in the policy analysis, and how they are reported to communicate the impacts of policies. These differences are illustrated in Figure S1. In GCAM and MESSAGE, carbon sequestration and emissions associated with biomass growth and land use changes are included in the agriculture and land use sectors, respectively. Both MoMo and Roadmap include upstream production and transportation $\mathrm{CO}_{2}$ and non- $\mathrm{CO}_{2}$ greenhouse gases $\left(\mathrm{CO}_{2} \mathrm{e}\right)$ emissions, and Roadmap also includes indirect land-use change emissions based on literature reviews. However, this study focuses only on tailpipe $\mathrm{CO}_{2}$ emissions, and biofuelderived carbon is not included here in order to have consistent reporting across studies. The system boundaries of $\mathrm{CO}_{2}$ emissions by each model characterized in this study are compared in Figure S1. These differences are particularly important in the analysis of biofuels and carbon policies.

\subsection{Mechanisms for policy analysis}

All four models have been applied extensively for policy analysis, in particular for energy efficiency standards, carbon policies (e.g. carbon taxes, temperature or emissions targets), monetary policy (e.g. subsidies), air pollution policies, etc. The mechanisms of policy analysis (e.g. exogenous vs. endogenous, constraints vs. cost-minimization vs. what-if analysis) are described in detail in Table S4. In general, GCAM and MESSAGE solve for travel activity and energy-related variables as a function of cost; thus are suited for price-based policies relying on cost adjustments (such as carbon prices) to drive change. MoMo and Roadmap are run primarily as backcasting analyses or for regulatory impact analysis, where parameters, such as the average rate of efficiency improvement, mode shares or activity levels, are typically set exogenously by the modelers.

\section{Base Year (2010) and Global Projections in the Baseline Scenario}

This section compares the consistency in the base year data and explores the baseline scenario projections in each of the four models. We discuss the reasons for similarities and differences in the base year and projections.

\subsection{Uncertainty in the base year (2010) estimates}

A key finding of the iTEM exercise is that there are considerable discrepancies in historical data, both globally and for individual countries. There are many reasons for data discrepancies across models. Calibration to different sources of historical data, or different versions of the same source (specifically the IEA Energy Balances) partly account for differences in transportation fuel consumption at an aggregate level (Figure S2). Models also make independent assumptions to disaggregate IEA energy balances to individual modes and technologies - for example to road, aviation, shipping; and within road energy consumption is further allocated to some combination of light-duty vehicles (LDVs), two and three-wheelers, buses, and freight heavy-duty trucks (HDT). As a result, mode-specific differences are much larger (Figure S3), especially for developing regions where there are relatively few data points for calibration to reconcile the differences.

Differences in energy consumption quantities also reflect differences in the estimates of (a) load or occupancy factors, (b) vehicle kilometers traveled (VKT) per vehicle, and/or (c) the number of 
vehicles in operation, and/or (d) different estimates of the energy intensity of these technologies. Variability in estimates of transportation activity - vehicle kilometers traveled (VKT) or service demand (PKT), and tonne-km for freight - are often much larger than the differences in estimated energy use (Figures S3 and S4). Detailed data for developing countries are sparsely available, if at all, necessitating assumptions largely on the basis of historical trends or data from other countries. Given the sparsely available data, models differ substantially in terms of assumed 2010 values for mode-specific vehicle stocks, energy intensity of service, annual VKT per vehicle, and occupancy factors by country (Figure 2). For example, estimated global passenger travel in buses for the year 2010 ranges from 6 to 20 trillion PKT and estimates of global road freight range from 9 to 18 trillion tonne-km. These differences are even greater for individual countries/regions (Figure 2). For China, the estimated PKT across all modes of transportation range from 4.4-10.3 billion PKT/year in 2010, a factor two difference. Similarly, the estimated total energy use for transport for 2010 range from 7.5-12.4 EJ. Uncertainty in these input parameters is much higher for developing regions like India where there are no reliable nation-wide travel surveys, systematic traffic counts or vehicle odometer readings, or a comprehensive database of on-road vehicles.

\subsection{Baseline scenario of global fuel consumption and $\mathrm{CO}_{2}$ emissions}

Across the four models, global transportation fuel consumption in a baseline scenario is projected to grow by anywhere from 1.5 to 2.5 times the 2010 level to reach 160-250 EJ by 2050 (Figure 3). All models project continued importance of liquid fuels - both fossil- and bio-based - and dominance of developing regions, which account for around two-thirds of total transportation energy consumption by 2050, from around half today. The modes that use the most energy continue to be car and light-duty trucks and heavy-duty trucks, though the share of aviation increases rapidly. The fastest growth is expected in the aviation sector (150 to 400\%) and road freight, or heavy-duty trucking (HDT), sector (100 to 160\%).

As discussed earlier in Section 2.4 and Figure S1, models differ in terms of the accounting of $\mathrm{CO}_{2}$ emissions, and how these emissions are reported in the iTEM exercise. The total $\mathrm{CO}_{2}$ emissions from transportation are estimated to be 11-18 Gigatonnes of $\mathrm{CO}_{2}$ in 2050 for the tank to wheel (TTW, or tailpipe) emissions, equivalent to combustion emissions. Biofuel-derived carbon is not included here in order to have consistent accouting across studies)(Figure 3).

Some of the variation in projected growth of transportation fuel consumption may be explained by differences in assumed growth in income (per capita GDP) - historically the key driver of vehicle ownership and travel (Schäfer et al. 2009). For example, China's per capita income in 2050 is assumed to range from $\$ 24,000$ (MESSAGE) to $\$ 42,000$ (MoMo) (2005 U.S. dollars, measured in purchasing power parity)(Figure S6), with corresponding estimates vehicle owernship of 172 (MESSAGE) to 426 (MoMo) per 10000 people. On the other hand, MoMo in general has a lower-than-average service demand projection, while Roadmap to have a higher one across all modes. Taking all these into account (assumptions about regional GDP growth, vehicle ownership, service demand, etc), global passenger mobility is expected to increase by 1.9-3.3 times from 2010 to 2050, ranging from 37 (MoMo)-59 (GCAM) trillion PKT in 2010 to 78 (MoMo)-136 (Roadmap) trillion PKT in 2050 (Figure S7). Air travel is expected to grow from 4.4-4.6 trillion PKT in 2010 to 17 (GCAM)-27 (Roadmap) trillion PKT in 2050, constituting 13$20 \%$ total passenger transportation service demand by 2050 , from today's $8-12 \%$.

\subsection{Light-duty vehicles and two-wheelers ownership projections}

Perhaps one of the most important uncertainties in projecting future fuel use is the level of vehicle ownership and use. Population and income growth are the key drivers of the expected increase in car ownership, though GCAM, MESSAGE, and Roadmap models predict ownership as a 
function of total travel, modal shares, and annual VKT per vehicle, MoMo estimate it directly from basic population and income data, as shown in Figure 1. Globally, baseline projections of global LDV (cars and light trucks) ownership rates (vehicles per 1,000 people) increase from around 120-160 in 2010 to 220 (GCAM)-320 (MESSAGE) in 2050 (Figure S6). This implies a growth in on-road stock from around $0.85-1.1$ billion LDVs in 2010 to $1.6-2.2$ billion LDVs in 2030 and 2.0-3.0 billion LDVs in 2050, when the world will have about 10 billion people (Figure S8). The range is consistent with the auto industry's own projections for the year 2035 (Navigant Consulting 2015). There are wide ranges in estimated vehicle ownership across countries: 7001,075 for the US by the middle of the century (US is around 700 today), $40-430$ for China, and 20-250 for India across the four models (Figure S6). In general, GCAM and MESSAGE project higher vehicle ownership for developed countries, and MoMo and Roadmap have higher projections for developing countries (Figure S6).

The amount of travel per vehicle per year was also found to be a significant source of uncertainty across the models. For some countries, models had widely varying assumptions for annual vehicle travel, especially for certain vehicle types (e.g. from 3,000 to $10,000 \mathrm{~km}$ per year for motor scooters in India). Since these assumptions link vehicle stock to total activity and fuel use, they need to be better understood. Improving the representation of car ownership and use across the models was identified as a priority, perhaps second only to data improvements.

\subsection{Freight projections}

All four models rely on GDP forecasts to project future freight demand (with different system boundaries, see Table S2). Regions have very different starting points for modal shares (trucks vs. rail vs. ship), and projections across the four models tend to hold the base year modal shares roughly constant through 2050. In reality, future evolution will depend on the characteristics of products (e.g. type of commodities) being shipped, availability of efficient freight technologies, and development policies and infrastructure. For example, policies can affect the type of fuel used (e.g., the upcoming MARPOL Annex VI on regional and global marine fuel oil (HFO) and marine diesel fuel use), as well as commodities transported domestically (e.g., reduced coal use in China to improve air quality and reduce GHG emissions) and internationally (e.g., liquefied natural gas (LNG) and oil exports from US).

\section{Climate Policy Scenario}

Comparing the results of policy impacts from multiple models with different solution mechanisms can improve our understanding of the robustness of the results. We compare a scenario consistent with the deep economy-wide decarbonization needed to reach a $2{ }^{\circ} \mathrm{C} / 450$ ppm target by the end of the century. In GCAM, this means applying carbon prices at levels that increase at a Hotelling schedule of 5\% per year from 2020 to 2050 such that $\mathrm{CO}_{2}$ emissions follow a $450 \mathrm{ppm}$ pathway. Similarly, a carbon budget is imposed in the MESSAGE model in order to reach the target of GHG concentration (including all forcing agents) peaks at just over $500 \mathrm{ppm}$ GHG around mid-century and then drops to $477 \mathrm{ppm}$ by 2100 . This leads to a globallyharmonized carbon price (across all countries and energy/land-use sectors) that grows over time with the prevailing model discount rate of 5\%. The price first comes into effect in 2020 at 43 $\$ / \mathrm{tCO}$ eq and then reaches $186 \$ / \mathrm{tCO}_{2} \mathrm{e}$ in 2050 . For MoMo, the $2{ }^{\circ} \mathrm{C}$ scenario is consistent with the ETP analysis that lays out a secure and affordable energy system deployment pathway and an emissions trajectory consistent with at least a $50 \%$ chance of limiting the average global temperature increase to $2{ }^{\circ} \mathrm{C}$ by 2100 (IEA 2014). Roadmap's low-carbon scenario only projects to 2030, and is based on identified policy potential to expand the adoption of new vehicle efficiency standards; increase uptake of electric-drive passenger vehicles; improve the efficiency 
of marine vessels and aircraft; shift some road-based travel to less carbon-intensive modes; and improve road freight logistics (Miller and Façanha 2014, Façanha, Blumberg, and Miller 2012).

Because of the different interpretations of the $2{ }^{\circ} \mathrm{C}$ scenario, this translates to different transportation sector GHG emission reduction levels across models. In addition, because GCAM and MESSAGE are IAMs, GHG emission reductions in transportation will compete with emission mitigation options elsewhere in the economy based on costs. What this indicates is that both the level and timing of mitigation can vary considerably across models. The overall GHG reductions range is estimated between 0.86 (MESSAGE) and 2.1 (Roadmap) $\mathrm{Gt} \mathrm{CO}_{2} / \mathrm{yr}$ in 2030, and between 2.0 (GCAM) and 3.6 (MESSAGE) $\mathrm{Gt} \mathrm{CO}_{2} / \mathrm{yr}$ in 2050 (Roadmap's low-carbon scenario only projects to 2030). The overall magnitude of transportation emissions reduction estimated is consistent with the range found by the literature assessment of the IPCC AR5 WGIII (IPCC 2014a). However the four models compared here provide more details on mode-specific mitigation measures, and better insight regarding the regional-level policies and measures necessary to mitigate in a manner that is consistent with the global goals. Here we compare the results in changes in per capita travel (Section 4.1), energy intensity of transportation service (Section 4.2), and carbon intensity of fuels (Section 4.3). We present the results of a decomposition analysis in Section 4.4.

\subsection{Passenger travel activity and fuel use}

In general, in response to a climate policy the four models project a decrease in overall private travel volumes (5-15\% reduction in 2050, except for Roadmap which does not generate 2050 results), but an increase in travel by public modes (Figure 4 and Figure S9 by region). In MoMo and Roadmap, these changes are estimated based on expert judgment (what-if scenarios). In GCAM and MESSAGE, travel demands are a function of income and travel time costs (both are exogenous), and other costs including fuel, levelized vehicle costs, and carbon taxes. Thus, the demand response in these IAMs is entirely a function of increase in travel costs as a result of implicit carbon tax, and the adoption of low-carbon fuels and vehicle technology. Corresponding to the reduction in average per capita travel is a decline in the stocks of LDVs and two-wheelers (7-25\% reduction of LDVs globally, equivalent to $150-740$ million less cars and light trucks in 2050 in the policy scenario compared to the baseline scenario) (Figure S10).

The overall fuel use by scenario, model, and transportation mode in 2030 and 2050 are shown in Figure 5. Even in the climate policy scenario, liquid fuels (including biofuels which are not separately reported by the models) are still dominant in the transportation sector in 2050, despite greater penetration of other alternative fuels, particularly electricity (in bus and rail, and in car and light-duty trucks) and natural gas (in car and light-duty trucks, heavy-duty trucks, and in international shipping). Overall fuel use decreases by 5-26\% in the climate policy scenario to $97-$ $127 \mathrm{EJ}$ in 2030 and $12-41 \%$ to $95-162 \mathrm{EJ}$ in 2050 (Figure 5). Liquids constitute $87-99 \%$ of total fuel use in the baseline scenario compared to $74-84 \%$ in climate policy scenario in 2050 .

\subsection{Energy intensity of transportation service}

All four models assume improvements in energy efficiency of vehicle technologies and show a gradual penetration of alternative fuel vehicles across all transportation technology/modes. In the baseline scenario, there are underlying trends shifting passenger service demand to faster modes (i.e. from public transit to cars and air travel), as discussed in Sections 2 and 3. Despite increases in the efficiency of vehicles (Figure S11), the overall energy intensity of passenger travel decreases much more slowly across all transportation modes, or even increases slightly for some regions such as China (Figure S11). These increases are due to modal shifting, towards more energy-intensive transportation modes, as well as income-related decreases in LDV occupancy factors. Climate policy results in greater reduction in energy intensity or slower increases in 
energy intensity in countries such as China. These changes reflect the combined effects of: (1) greater efficiency improvements of transportation technology including vehicles (Figure S11); (2) shifts to more energy-efficient low-carbon technologies such as electric vehicles; and (3) shifts to more energy-efficient low-carbon modes. In the climate policy scenario, the levelized costs of travel in energy intensive modes - air travel and LDV - rise more than those of buses and rail. As a result, the share of more energy-efficient public transit modes increases, leading to slower increases or decreases in average MJ/PKT.

It is interesting to note that the reductions in energy intensity from the baseline to policy scenarios are greater for the transportation-only models (MoMo and Roadmap) than the energy-economic systems models (GCAM and MESSAGE)(Figure 6). One possible explanation for the difference between the two types of models is that in the energy-economic systems models, the costs of mitigation are compared across all sectors, and the costs of efficiency improvement (particularly through the adoption of advanced vehicles such as electric vehicles). Similarly, the energy intensity of road freight (HDT) also has the similar trend: the energy intensity of freight shows almost no change in the energy-economic systems models between the baseline and policy scenarios while the reductions in the expert-based models can be much larger.

\subsection{Carbon intensity of fuels}

As discussed earlier in Sections 2.4 and 3.2 and Figure S1, models differ in terms of their accounting of carbon emissions, and how these emissions are reported in the iTEM exercise. Hence, a consistent comparison of fuel CI trends across models is not possible. However, within a given model, the relative trends between the baseline and climate policy scenarios highlight the extent of transportation sector decarbonization estimated by the models. All models except Roadmap include substantial de-carbonization of all transportation fuels especially liquids (via biofuels) in the climate policy scenario (Figure 7 and Figure S2). The largest CI reduction comes from GCAM and MESSAGE, followed by MoMo and least reductions from Roadmap.

\subsection{Decomposition of GHG emission reduction}

Here we decompose the relative roles of various mitigation drivers in achieving carbon emissions reductions from the passenger transportation sector from 2010 to 2050. Understanding how models use these different "levers" to achieve $\mathrm{CO}_{2}$ reductions can yield insights into the potential contribution of different strategies. Following the Kaya relationship developed previously (Zhang and Ang 2001, Ang 2004), $\mathrm{CO}_{2}$ emission reductions from passenger transportation sector in any given year can be represented by changes in travel demand, mode share, load factor (LF, or occupancy factor), energy intensity of modes, and the carbon intensity of fuels (Mishra et al. 2014). The equations for the decomposition analysis are listed in Appendix A of the SI. Figure 8 shows the results of the decomposition.

Among all mitigation options, all four models seem to indicate that efficiency improvements and low carbon fuels are the most important emission reduction strategies over the first half of the century, followed by mode shift, changes in LF of a particular mode, and travel demand reduction. The economic-based IAMs (GCAM and MESSAGE) favor the use of low carbon fuels as the primary mitigation option (most cost-effective transportation solution across the entire transportation sector, considering other options in transportation and other sectors) followed by efficiency improvements, whereas transportation-only and expert-based models (MoMo and Roadmap) favor efficiency improvements of vehicles followed by mode shifts. Roadmap, though going only to 2030, appears to be headed in a fairly similar direction as MoMo (despite higher baseline emissions), in particular in relying on vehicle efficiency improvements to achieve $\mathrm{CO}_{2}$ reductions. In the energy-economic system models (GCAM and MESSAGE), the cost of travel demand reduction and mode shifts (that are dominated by wage rate) are simply too expensive 
compared with other mitigation options. None of the models shows significant $\mathrm{CO}_{2}$ reductions related to load factor changes or reductions in overall travel demand relative to the baseline. Despite $2-5 \%$ reductions in total PKT between the baseline and the climate policy scenarios (Figure 4), it translates to only $0.3-4 \%$ of total GHG emission reductions in 2030 and 2050. In the case of MoMo, this reflects a modeling choice to hold the low $\mathrm{CO}_{2}$ travel levels the same as for the BAU; the goal was to achieve a low-carbon future without any reductions in mobility, as measured by PKT.

Note that because GCAM and MESSAGE only report combustion emissions in this iTEM exercise and biofuels are reported as carbon neutral, land use emissions (both direct and indirect) associated with increased demand for biofuels are reported elsewhere in the IAMs (mainly in the agriculture and land use sectors) instead of the transportation sector, the principle focus of iTEM. Nonetheless, the IAMs still find biofuels a cost-effective solution across the entire system.

\section{Policy Insights and Recommendations for Future Work}

The four models selected for this exercise have a long tradition of providing insights related to transportation-related activity, energy, economic and environmental projections and scenarios that are used to inform policy makers in many countries. Our goals in undertaking this modeling comparison focus on the details of the transportation models that are important for reported highlevel outcomes. In particular, we seek to understand how differences in the models' structures, key assumptions and data sources contribute to differences and similarities in the base year data and future projections. More importantly, given the policy relevance of these models, we seek to translate the findings from this study into relevant policy implications such as additional policy targets needed, feasibility of policy goals, regional vs. global reductions, etc. Through this effort, we also seek to identify major gaps, new efforts in modeling and data collection, future comparisons, and other next steps that would be of value to modelers and policymakers. Compared with previous modeling comparison efforts that are limited to IAMs (Pietzcker et al. 2014, Girod et al. 2013, Edelenbosch, McCollum, et al. 2016), we include two prominent transportation-only expert models that have been relied heavily in the past to inform policymakers about regional/country-specific/global transportation challenges. The value of this workshop extends beyond modeling comparison by bringing the academic institutions, NGOs, industry, and policymakers to have a real dialog about model assumptions and real-world policy targets (see Section 5.1 on the EV vehicle goals and the vehicle efficiency legislation in different countries). Our workshop also results in a list of survey of experts' recommendations for future work, summarized in Section 5.2

\subsection{Policy insights}

One useful exercise is to compare modeling results with planned policy targets to gain insights such as possible policy gaps, or the feasibility of modeling results. For example, the modeling results suggest that in order to be consistent with the global target of $2{ }^{\circ} \mathrm{C} / 450 \mathrm{ppm}$ the fleet average (stock) efficiency target for light-duty vehicles (cars and light trucks) should be around $2.2 \mathrm{MJ} / \mathrm{km}(1.8-2.8)$ for the US and $1.7 \mathrm{MJ} / \mathrm{km}(1.5-2.0)$ for China in 2030 and $1.7 \mathrm{MJ} / \mathrm{km}(1.3-$ 2.3) for US and $1.4 \mathrm{MJ} / \mathrm{km}$ (1.1-1.7) for China in $2050^{1}$ (Figure S11). Since US vehicle stocks are historically less efficient and bigger sizes, the expected vehicle stock efficiency improvement to meet the $2{ }^{\circ} \mathrm{C} / 450 \mathrm{ppm}$ has a wider range compared to China depending on each model's assumptions regarding size changes and consumers' preference for changes toward smaller and more efficient vehicles. Based on Figure 9, the current and proposed fuel economy standards for

${ }^{1} 2.2 \mathrm{MJ} / \mathrm{KM}$ is equivalent to 34 miles per gasoline gallon equivalent (mpgge), and $1.7 \mathrm{MJ} / \mathrm{KM}$ is roughly equivalent to 44 mpgge. 
new light-duty vehicles ${ }^{2}$ in US and China are probably insufficient to meet the fleet-average target for 2030. ${ }^{3}$ Though if future standards continue to be tightened at rates consistent with current policies, efficiency could certainly deliver its contribution to the $2{ }^{\circ} \mathrm{C} / 450 \mathrm{ppm} \mathrm{CO}_{2} \mathrm{e}$ target.

Another policy insight, as shown in Table 2, is the comparison between existing policy commitments for zero-emission vehicles (ZEVs) and partial ZEVs (plug-in hybrid vehicles and hydrogen fuel cell vehicles) and the projected levels that the models suggest need to be on the road by $2020 / 2025$ in order for the transportation sector to be consistent with the $2{ }^{\circ} \mathrm{C}$ target. This comparison suggests that the current policy commitments toward EVs and PHEVs for 2020/2025 may be far below the number of vehicles suggested needed in 2025 by these models. The electric vehicle landscape is changing rapidly, however. For instance, the IEA's ETP 2016 suggests that EV sales growth in 2015 puts them potentially 'on-track' to meeting the two-degree targets by 2025 (assuming annual growth in sales can be sustained at levels close to those of that year) (IEA 2016). In general, the modeled low-carbon scenarios will require much more aggressive market uptake of EVs than targeted by policy commitments to date. This seems to indicate the need for stronger, coordinated policies to realize the combined mitigation potential of fuel economy standards and ZEV targets in both the near-term and long-term. As we illustrate in Figure 8, however, when comparing specific mitigation options (such as technology adoption or low carbon fuels) across models, it is worth noting that results must be understood in the context of emissions tradeoffs made in the models (i.e. more aggressive reliance on low carbon fuels will require less EVs to meet a particular target, and vice versa). Therefore, to the extent that greater reductions can be achieved from other measures such as mode shifts or demand reductions, the demand for EVs to meet the policy targets can be smaller.

\subsection{Recommendations for future work}

A survey was conducted with external experts not previously involved in the iTEM exercise (selected participants are listed in Acknowledgement and a full list of participants is available upon request), seeking inputs for key research priorities in the areas of data collection/development, model improvement, and model comparison. Each participant cast up to two votes in each category, and the results are summarized in the following bar graphs (Figure 10). Overall, experts see importance in improving the quality and the availability of data, as well as making improvements in model structure to enhance our capability of making better projections, especially of vehicle ownership and travel behaviors. The results are briefly discussed below.

Data. Given the great uncertainty observed in base year data across models, there is a great need to increase the collection of data, particularly in developing countries where systematic efforts in collecting transportation relevant data at the national level are lacking.

Model improvement. The lack of modeling of behavioral aspects in vehicle adoption rates, mobility/mode choices, urban vs. rural considerations, and so on are considered as critical to improve modeling efforts in the future. For example, modeling saturation in vehicle ownership

\footnotetext{
2 Note that these numbers have not been adjusted for the new European Worldwide Harmonized Light Vehicles Test Procedure that better reflects the real-world driving conditions. It is estimated that the new testing procedure will add on average 5-7 $\mathrm{gCO}_{2} / \mathrm{km}$ to the 2020/2021 EU standard (Mock et al. 2014) though the difference will be even larger for plug-in hybrid electric vehicles (Plötz, Funke, and Jochem 2015).

${ }^{3}$ The average vehicle lifetime in the US is about 15 years, and it takes about $16-20$ years for the entire vehicle stock to reach the same energy efficiency level of the new vehicles sold in a given year.
} 
and use as a function of income distributions, urban form, and infrastructure requirements and constraints, was discussed as an important enhancement that could be made to these models. An improved representation of the freight sector is also an area of future research. A few recent modeling efforts have started to address these critical issues: (Bunch et al. 2015, McCollum et al. 2016, ÓBroin and Guivarch 2016, Carrara and Longden 2016).

As we have shown in this paper, detailed comparison of modeling data and results at country/regional level and specific modes show greater uncertainties and differences than the global and aggregated data for the base year, baseline projections and the climate policy scenario. Better regional and demographic detail could improve the capacity of models to better inform policy goals and estimate policy impacts. Further, for large regions like China, variation at the sub-regional level in current and projected income, urbanization rates, vehicle ownership, levels of infrastructure, types of industry, etc. may add further value to the analysis (Kishimoto et al. 2014). Similarly, modeling strata of demographic groups can provide better understanding of vehicle ownership levels, travel behavior, response to GDP growth and policies, etc.

Modeling comparison. In future model comparison work, external experts see great value in conducting on-going, coordinated efforts in aligning input assumptions and historical data, more analysis of vehicle ownership, and more policy analysis, among other topics.

\section{Acknowledgement}

We acknowledge contributions by International Transportation Energy Modeling (iTEM) workshop participants, particularly presentations by Paul Kishimoto (MIT), Hiroyuki Kaneko (Nissan) and John Maples (EIA); and the valuable inputs and discussions provided by panelists (Robert Spicer, BP; Paul Tanaka, ExxonMobil; Rebecca Lindland, KAPSARC; and Jake Ward at DOE). Financial support for the workshop was generously provided by the US DOE Vehicle Technologies Office, University of California Research Initiatives, and BP. DM acknowledges funding provided by the ADVANCE project (FP7/2007-2013, grant agreement No. 308329) of the European Commission. 


\section{Figure captions}

Figure 1. Simplified representation of how models solve for personal light-duty vehicle (LDV) and two wheelers $(2 \mathrm{~W})$ demand. Circles are exogenous variables, boxes are endogenous calculations by the model and text without boxes are methods of solving for a particular variable. Color of the boxes represents similar variables across different models. Parc stands for "population of vehicles on the road." VKT is vehicle kilometers travelled whereas PKT is passenger kilometers travelled. ${ }^{4}$

Figure 2. Base year (2010) estimates of transportation activity by mode in China, India, EU-27 and the U.S. 2W \& 3W: two- and three-wheelers; LDV: light-duty vehicle; HDT: heavy-duty truck; Pass. Rail: passenger rail; D. Ship \& Rail (F): domestic freight shipping \& rail; Int. Ship: international shipping; PKT: passenger kilometers travelled; VKT: vehicle kilometers travelled; TTW: Tank-to-wheel (or tailpipe) $\mathrm{CO}_{2}$ emissions (biofuel-derived carbon is not included here in order to have consistent accounting across studies).

Figure 3. Global fuel use and $\mathrm{CO}_{2}$ emission projections by mode to 2050 in the baseline scenario. 2W \& 3W: two- and three-wheelers; LDV: light-duty vehicle; HDT: heavy-duty truck; Pass. Rail: passenger rail; D. Ship \& Rail (F): domestic freight shipping \& rail; Int. Ship: international shipping; PKT: passenger kilometers travelled; VKT: vehicle kilometers travelled; TTW: Tankto-wheel (or tailpipe) $\mathrm{CO}_{2}$ emissions (biofuel-derived carbon is not included here in order to have consistent accounting across studies).

Figure 4. Global passenger activity in the baseline (B) and climate policy (CP) scenarios in 2010, 2030 and 2050.

Figure 5. Global fuel use in the baseline (B) and climate policy (CP) scenarios in 2010, 2030 and 2050. Liquids include crude oil, other fossil-fuel based liquids like CTL and GTL, and biofuels.

Figure 6. Average energy intensity of selected modes of transport. VKT: vehicle kilometers travelled. HDT: heavy-duty truck. LDV: light-duty vehicle

Figure 7. Carbon intensity of all transportation fuels in baseline and climate policy scenarios. Only combustion emissions are reported here; biofuels are reported here as carbon neutral.

Figure 8. Decomposition of the relative roles of mitigation options in reducing global carbon emissions from passenger transportation (including $2 \mathrm{~W} \& 3 \mathrm{~W}$, bus, LDV, passenger rail, and air travel).

Figure 9. Comparison of iTEM results with current and planned energy intensity policies for new passenger LDVs, by country (ICCT 2015), and the ranges of average energy intensity for the entire vehicle stock for 2030 and 2050 across the iTEM models. The stock averages are overlapped onto new vehicle standards by a 20 -year lag.

Figure 10. Survey of experts' recommendations for future improvement in data, modeling and modeling comparison.

${ }^{4} \mathrm{PKT}$ is related to VKT through the number of passengers per vehicle, which is sometimes called the load factor or the occupancy rate. Vehicle survival rate is the lifetime of vehicles, 


\section{Reference}

Ang, B. W. 2004. "Decomposition analysis for policymaking in energy:: which is the preferred method?" Energy Policy 32 (9):1131-1139. doi: http://dx.doi.org/10.1016/S0301-4215(03)00076-4.

Bunch, David S, Kalai Ramea, Sonia Yeh, and Christopher Yang. 2015. Incorporating Behavioral Effects from Vehicle Choice Models into Bottom-Up Energy Sector Models. Research Report - UCD-ITS-RR-15-13. Institute of Transportation Studies, University of California, Davis.

Carrara, Samuel, and Thomas Longden. 2016. "The Potential Impact of Road Freight on Climate Policy." Transportation Research Part D:submitted.

Clarke, John F., and J. A. Edmonds. 1993. "Modelling energy technologies in a competitive market." Energy Economics:123-129.

Creutzig, Felix, Patrick Jochem, Oreane Y. Edelenbosch, Linus Mattauch, Detlef P. van Vuuren, David McCollum, and Jan Minx. 2015. "Transport: A roadblock to climate change mitigation?" Science 350 (6263):911-912. doi: 10.1126/science.aac8033.

Di Vittorio, A. V., L. P. Chini, B. Bond-Lamberty, J. Mao, X. Shi, J. Truesdale, A. Craig, K. Calvin, A. Jones, W. D. Collins, J. Edmonds, G. C. Hurtt, P. Thornton, and A. Thomson. 2014. "From land use to land cover: restoring the afforestation signal in a coupled integrated assessment-earth system model and the implications for CMIP5 RCP simulations." Biogeosciences 11 (22):64356450. doi: 10.5194/bg-11-6435-2014.

Edelenbosch, O., G. Luderer, Detlef van Vuuren, K. Riahi, D. McCollum, C. Betram, Hana Daly, S. Carrara, I. Charalampdis, S. Fujimori, and E. O Broin. 2016. "Comparing transport model results based on kaya identities and identifying which underlying processes results in emission mitigation in a 2 degree scenario." Transportation Research Part C: Global transport projections for integrated assessment.

Edelenbosch, O. Y., D. L. McCollum, D. P. van Vuuren, C. Bertram, S. Carrara, H. Daly, S. Fujimori, A. Kitous, P. Kyle, E. Ó Broin, P. Karkatsoulis, and F. Sano. 2016. "Decomposing passenger transport futures: Comparing results of global integrated assessment models." Transportation Research Part D: Transport and Environment. doi: http://dx.doi.org/10.1016/i.trd.2016.07.003.

Façanha, Cristiano, Kate Blumberg, and Josh Miller. 2012. Global transportation energy and climate roadmap. The International Council on Clean Transportation.

Fawcett, Allen A., Gokul C. Iyer, Leon E. Clarke, James A. Edmonds, Nathan E. Hultman, Haewon C. McJeon, Joeri Rogelj, Reed Schuler, Jameel Alsalam, Ghassem R. Asrar, Jared Creason, Minji Jeong, James McFarland, Anupriya Mundra, and Wenjing Shi. 2015. "Can Paris pledges avert severe climate change?" Science. doi: 10.1126/science.aad5761.

Fulton, Lew, Pierpaolo Cazzola, and François Cuenot. 2009. "IEA Mobility Model (MoMo) and its use in the ETP 2008." Energy Policy 37 (10):3758-3768. doi: http://dx.doi.org/10.1016/j.enpol.2009.07.065. 
Girod, Bastien, Detlef P. Vuuren, Maria Grahn, Alban Kitous, Son H. Kim, and Page Kyle. 2013. "Climate impact of transportation A model comparison." Climatic Change 118 (3):595-608. doi: 10.1007/s10584-012-0663-6.

ICCT. 2015. "Global passenger vehicle standards." http://www.theicct.org/globalpv-standards-chart-library.

IEA. 2014. Energy Technology Perspectives 2014. International Energy Agency.

IEA. 2016. Energy Technology Perspectives 2016 - Mobilising Innovation to Accelerate Climate Action. International Energy Agency.

IPCC, ed. 2014a. Climate Change 2014: Mitigation of Climate Change. Contribution of Working Group III to the Fifth Assessment Report of the Intergovernmental Panel on Climate Change. Edited by O. Edenhofer, R. Pichs-Madruga, Y. Sokona, E. Farahani, S. Kadner, K. Seyboth, A. Adler, I. Baum, S. Brunner, P. Eickemeier, B. Kriemann, J. Savolainen, S. Schlömer, C. von Stechow, T. Zwickel and J.C. Minx. Cambridge, United Kingdom and New York, NY, USA: Cambridge University Press.

IPCC. 2014b. Climate Change 2014: Synthesis Report. Contribution of Working Groups I, II and III to the Fifth Assessment Report of the Intergovernmental Panel on Climate Change [Core Writing Team, R.K. Pachauri and L.A. Meyer (eds.)]. IPCC, Geneva, Switzerland, $151 \mathrm{pp}$.

Kim, Son H., Mohamad Hejazi, Lu Liu, Katherine Calvin, Leon Clarke, Jae Edmonds, Page Kyle, Pralit Patel, Marshall Wise, and Evan Davies. 2016. "Balancing global water availability and use at basin scale in an integrated assessment model." Climatic Change:1-15. doi: 10.1007/s10584-016-1604-6.

Kishimoto, Paul, Da Zhang, Xiliang Zhang, and Valerie Karplus. 2014. "Modeling Regional Transportation Demand in China and the Impacts of a National Carbon Policy." Transportation Research Record: Journal of the Transportation Research Board 2454:1-11. doi: doi:10.3141/2454-01.

Kyle, P., and S.H. Kim. 2011. "Long-term implications of alternative light-duty vehicle technologies for global greenhouse gas emissions and primary energy demands." Energy Policy 39 (5):3012-3024.

McCollum, D., Charlie Wilson, H. Pettifor, Kalai Ramea, V. Krey, K. Riahi, C. B. Lin, O. Y. Edelenbosch, and S. Fujisawa. 2016. "Improving the behavioral realism of global integrated assessment models: an application to consumers' vehicle choices." Transportation Research Part D:Forthcoming.

McCollum, David, Volker Krey, Peter Kolp, Yu Nagai, and Keywan Riahi. 2013. "Transport electrification: A key element for energy system transformation and climate stabilization." Climatic Change 123 (3):651-664. doi: 10.1007/s10584-013-0969-z.

McJeon, Haewon, Jae Edmonds, Nico Bauer, Leon Clarke, Brian Fisher, Brian P. Flannery, Jerome Hilaire, Volker Krey, Giacomo Marangoni, Raymond Mi, Keywan Riahi, Holger Rogner, and Massimo Tavoni. 2014. "Limited impact on decadal-scale climate change from increased use of natural gas." Nature 514 (7523):482-485. doi: 10.1038/nature13837

http://www.nature.com/nature/journal/v514/n7523/abs/nature13837.html supplementary-information. 
Miller, Joshua D., and Cristiano Façanha. 2014. State of Clean Transport Policy: A 2014 Synthesis of Vehicle and Fuel Policy Developments. The International Council on Clean Transportation.

Mishra, Gouri Shankar, Page Kyle, Jacob Teter, Geoffrey M. Morrison, Son Kim, and Sonia Yeh. 2013. Transportation Module of Global Change Assessment Model (GCAM): Model Documentation. Research Report UCD-ITS-RR-13-05. Davis, CA: Institute of Transportation Studies, University of California.

Mishra, Gouri Shankar, Saleh Zakerinia, Sonia Yeh, Jacob Teter, and Geoff Morrison. 2014. "Mitigating climate change: Decomposing the relative roles of energy conservation, technological change, and structural shift." Energy Economics 44 (0):448-455. doi: http://dx.doi.org/10.1016/i.eneco.2014.04.024.

Mock, Peter, Jörg Kühlwein, Uwe Tietge, Vicente Franco, Anup Bandivadekar, and John German. 2014. The WLTP: How a new test procedure for cars will a ect fuel consumption values in the EU. The International Council on Clean Transportation (ICCT) working paper 2014-9.

Navigant Consulting, Inc., . 2015. Transportation Forecast: Light Duty Vehicles Global Market Forecasts, 2015-2035.

ÓBroin, Eoin, and C. Guivarch. 2016. "Transport infrastructure costs in low-carbon pathways." Transportation Research Part D:submitted.

Pietzcker, Robert C., Thomas Longden, Wenying Chen, Sha Fu, Elmar Kriegler, Page Kyle, and Gunnar Luderer. 2014. "Long-term transport energy demand and climate policy: Alternative visions on transport decarbonization in energyeconomy models." Energy 64:95-108. doi: http://dx.doi.org/10.1016/j.energy.2013.08.059.

Plötz, Patrick, Simon Funke, and Patrick Jochem. 2015. Real-world fuel economy and $\mathrm{CO} 2$ emissions of plug-in hybrid electric vehicles. Working Paper Sustainability and Innovation, No. S1/2015.

Riahi, Keywan, Frank Dentener, Dolf Gielen, Arnulf Grubler, Jessica Jewell, Zbigniew Klimont, Volker Krey, David McCollum, Shonali Pachauri, Shilpa Rao, Bas van Ruijven, Detlef P. van Vuuren, and Charlie Wilson. 2012. "Chapter 17 - Energy Pathways for Sustainable Development." In Global Energy Assessment Toward a Sustainable Future, 1203-1306. Cambridge University Press, Cambridge, UK and New York, NY, USA and the International Institute for Applied Systems Analysis, Laxenburg, Austria.

Schäfer, Andreas, John B. Heywood, Henry D. Jacoby, and Ian A. Waitz. 2009. Transportation in a Climate-Constrained World: The MIT Press.

Schäfer, Andreas, and D. G. Victor. 2000. "The future mobility of the world population." Transportation Research Part A34:171-205.

Schipper, Lee, Calanit Saenger, and Anant Sudardshan. 2011. "Transport and Carbon Emissions in the United States: The Long View." Energies 4:563-581. doi: doi:10.3390/en4040563.

Tavoni, Massimo, Elmar Kriegler, Keywan Riahi, Detlef P. van Vuuren, Tino Aboumahboub, Alex Bowen, Katherine Calvin, Emanuele Campiglio, Tom Kober, Jessica Jewell, Gunnar Luderer, Giacomo Marangoni, David McCollum, Mariesse van Sluisveld, Anne Zimmer, and Bob van der Zwaan. 2015. "Post2020 climate agreements in the major economies assessed in the light of 
global models." Nature Clim. Change 5 (2):119-126. doi:

10.1038/nclimate2475

http://www.nature.com/nclimate/journal/v5/n2/abs/nclimate2475.html supplementary-information.

van der Zwaan, B. C. C., H. Rösler, T. Kober, T. Aboumahboub, K. V. Calvin, D. E. H. J. Gernaat, G. Marangoni, and D. McCollum. 2013. "A cross-model comparison of global long-term technology difussion under a $2^{\circ} \mathrm{C}$ climate change control target." Climate Change Economics 04 (04):1340013. doi: doi:10.1142/S2010007813400137.

Zhang, F. Q., and B. W. Ang. 2001. "Methodological issues in cross-country/region decomposition of energy and environment indicators." Energy Economics 23 (2):179-190. doi: http://dx.doi.org/10.1016/S0140-9883(00)00069-4. 


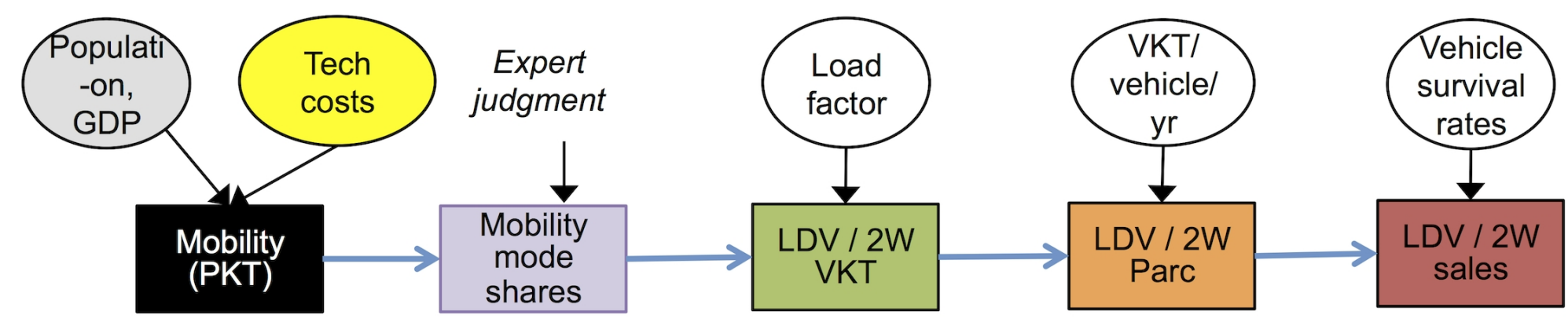

\section{Roadmap}

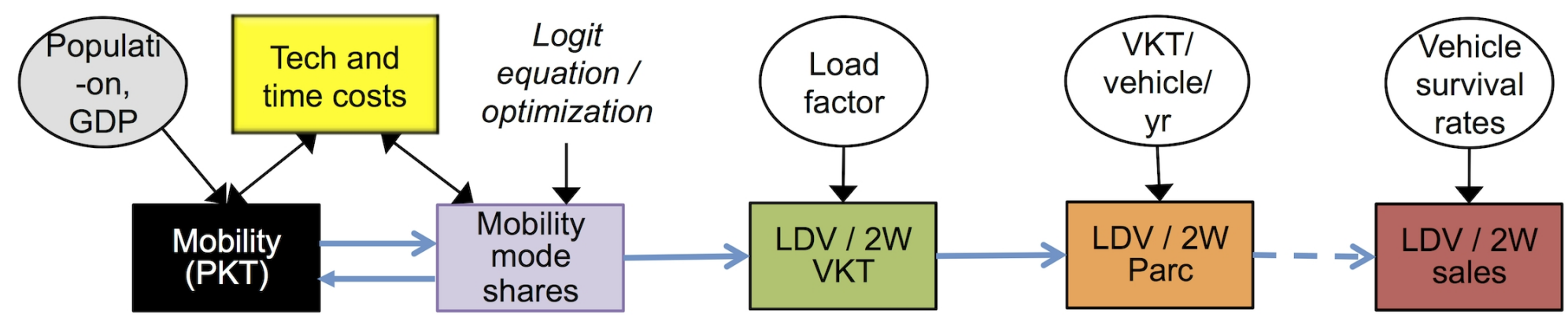

\section{GCAM MESSAGE}

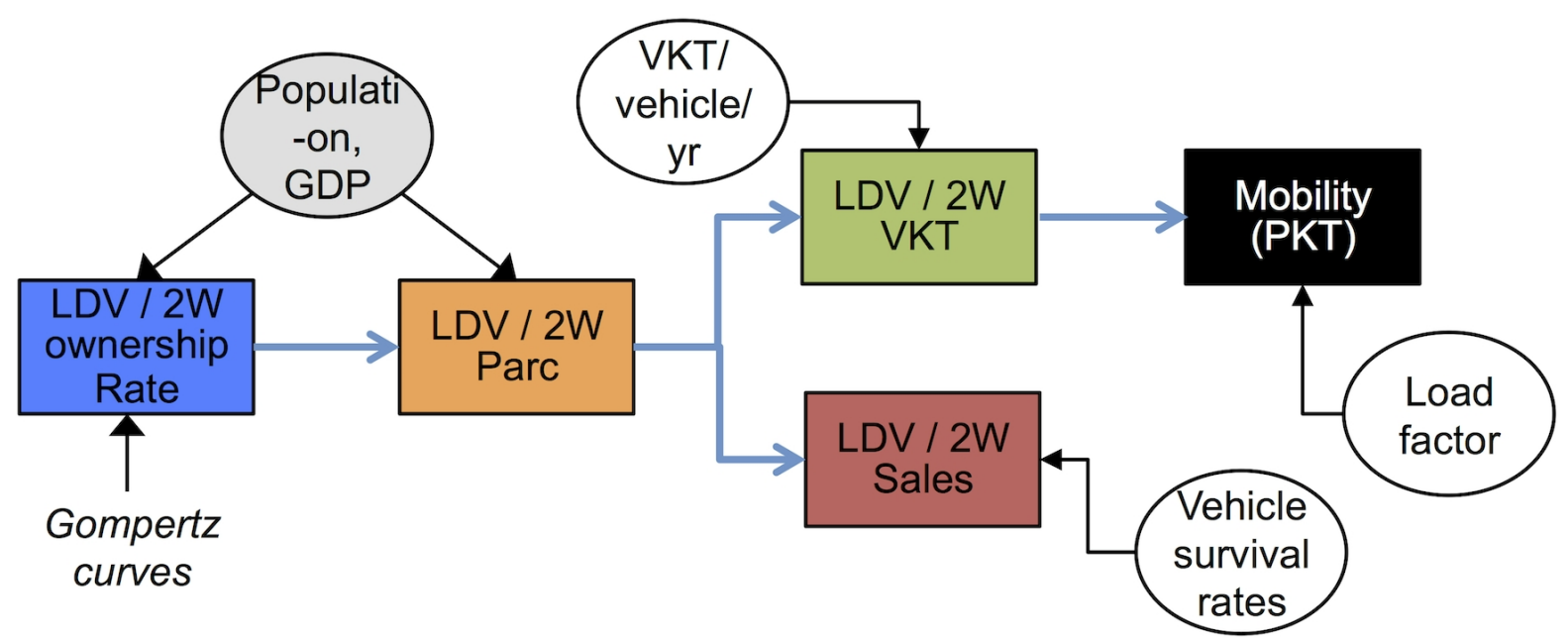

MoMo 

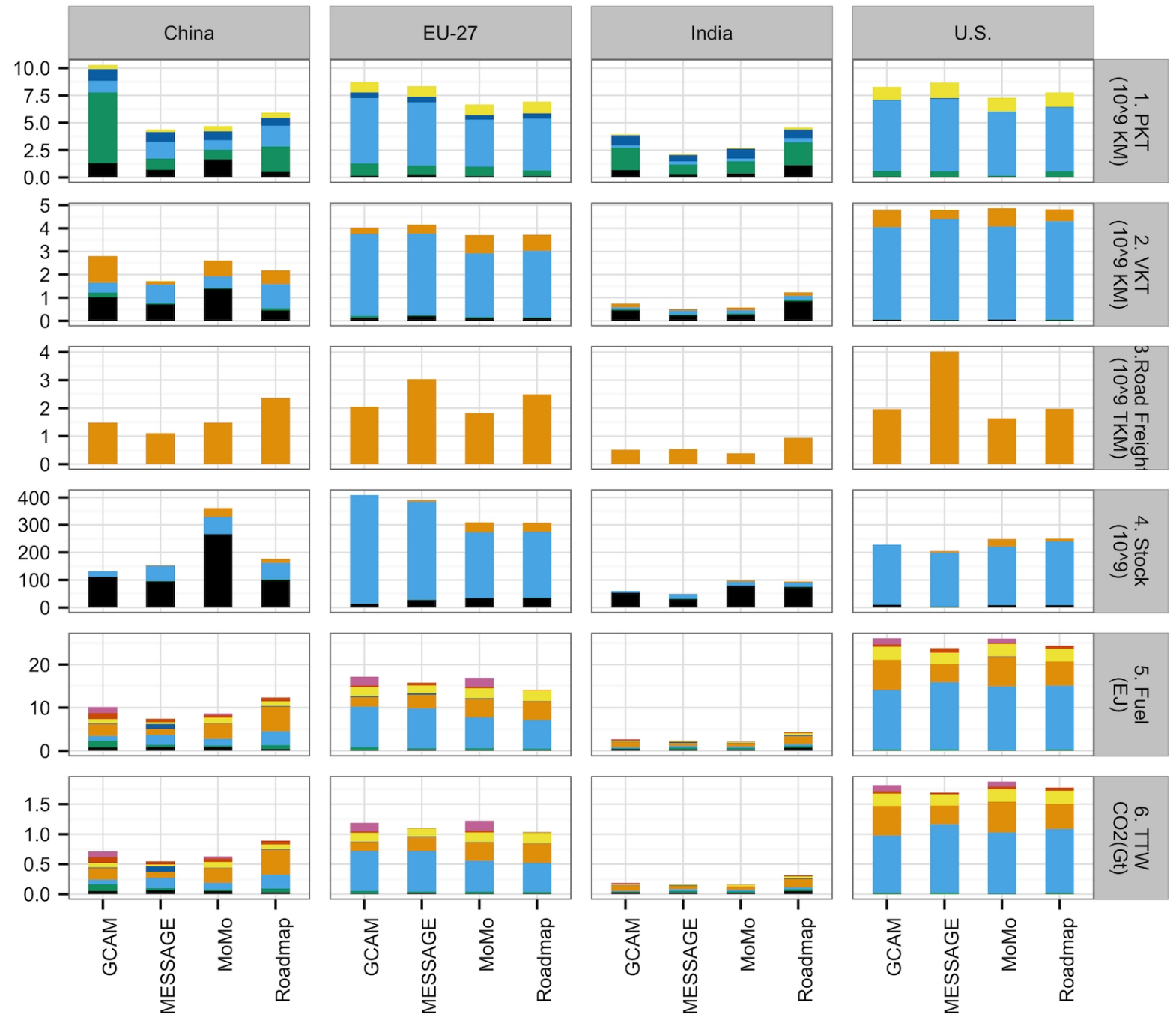

Base Year (2010)

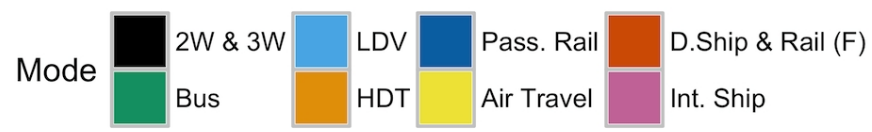




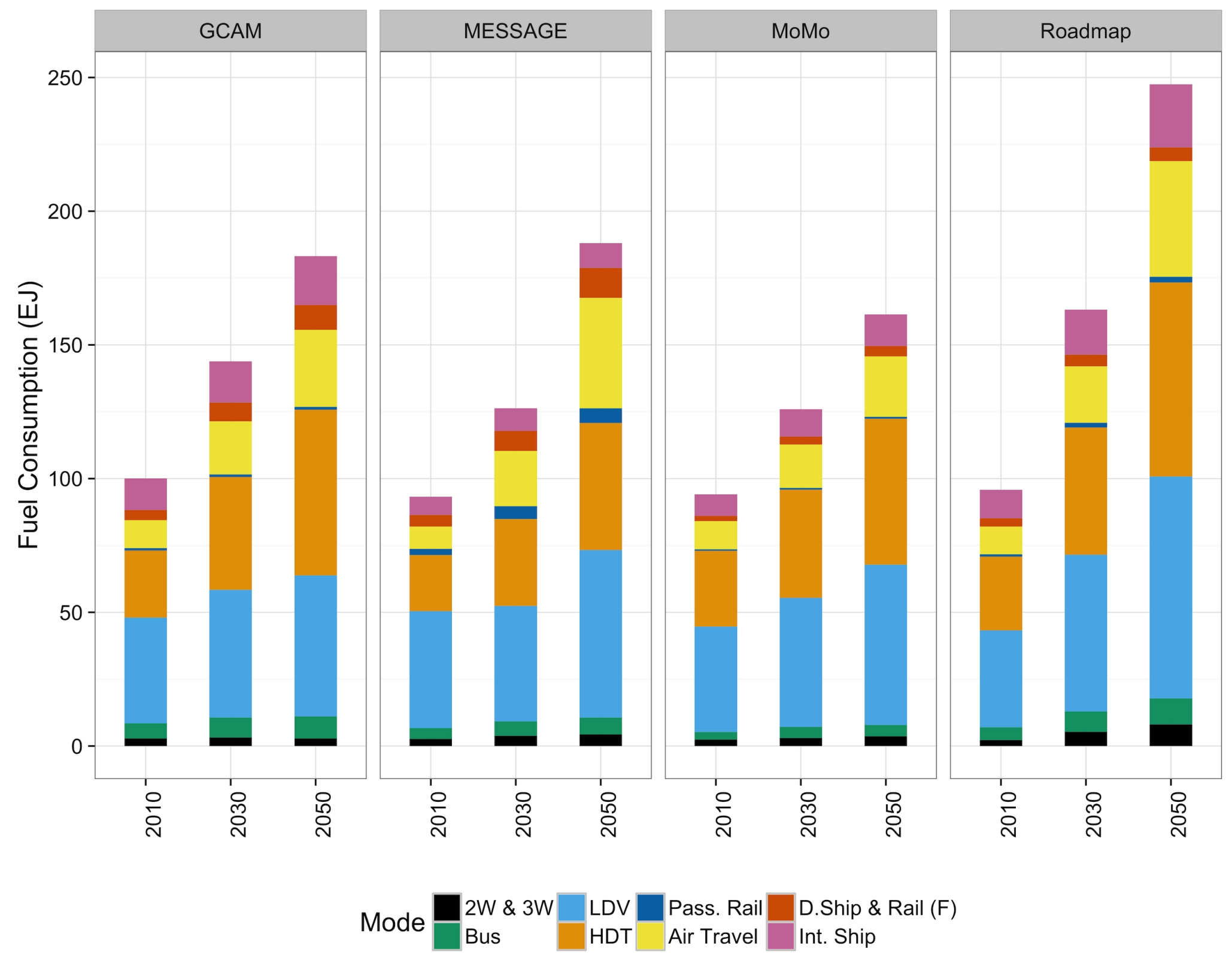




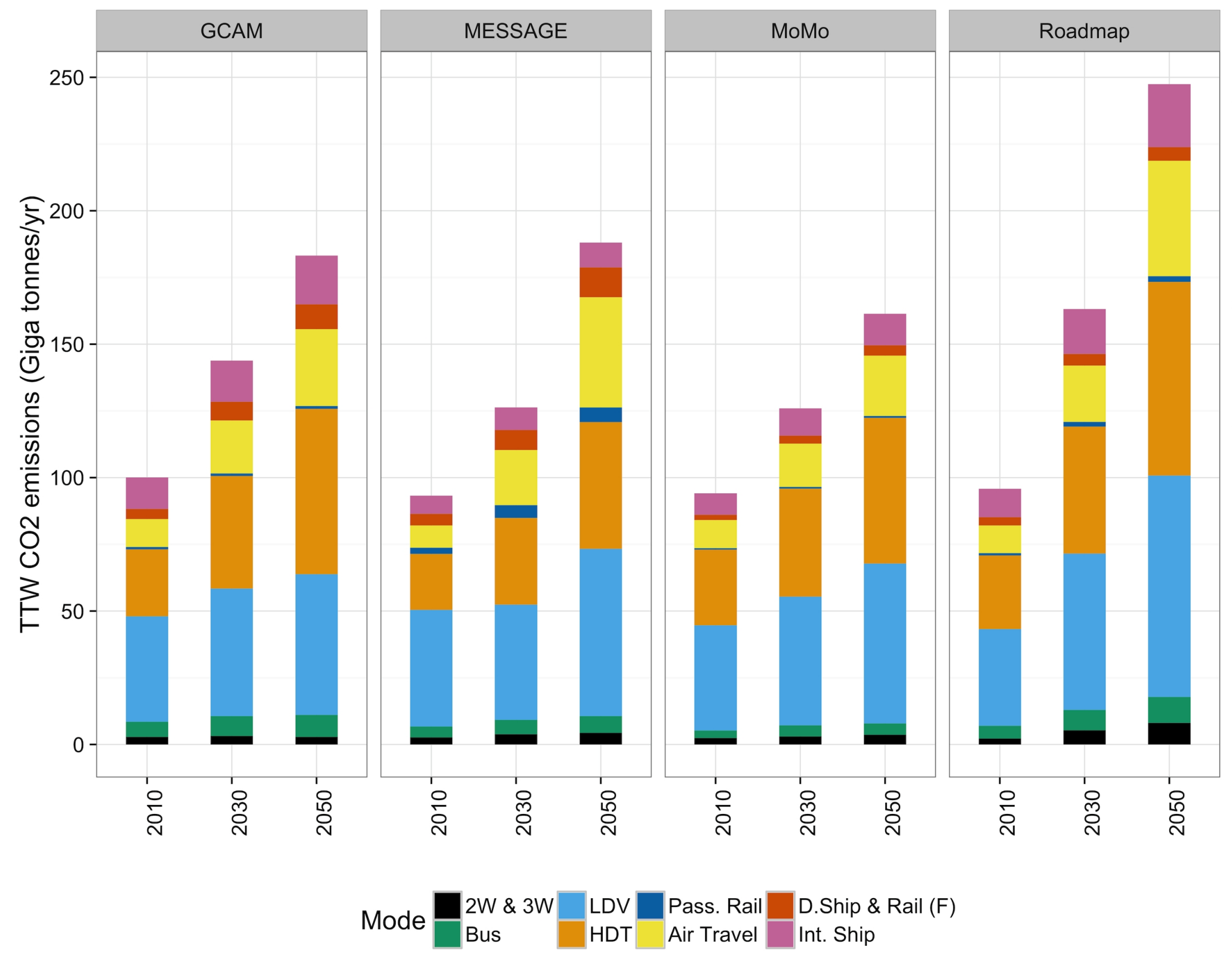




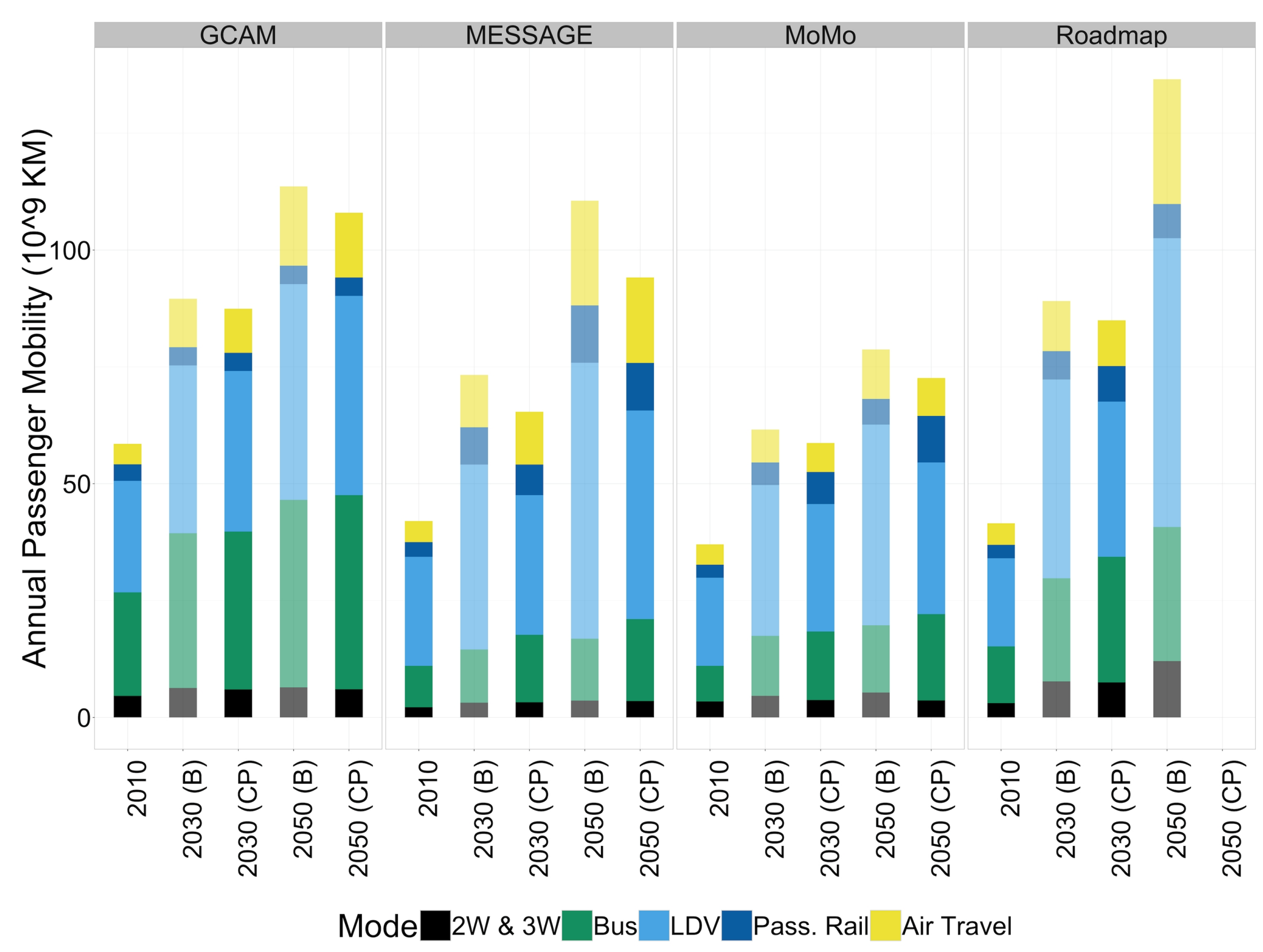




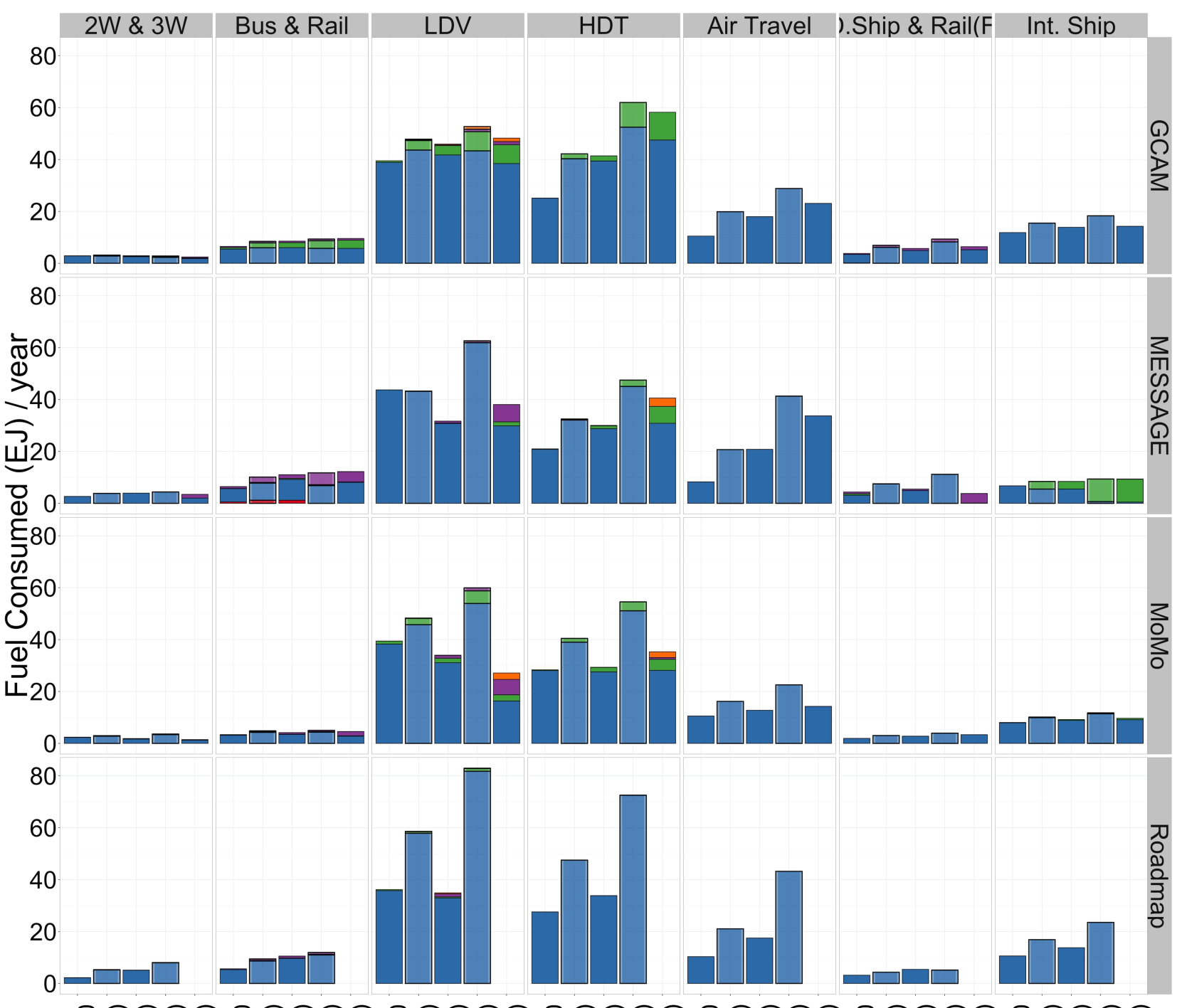

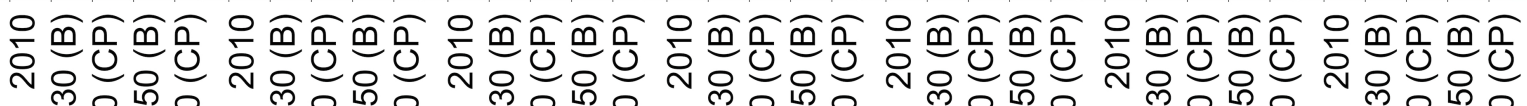

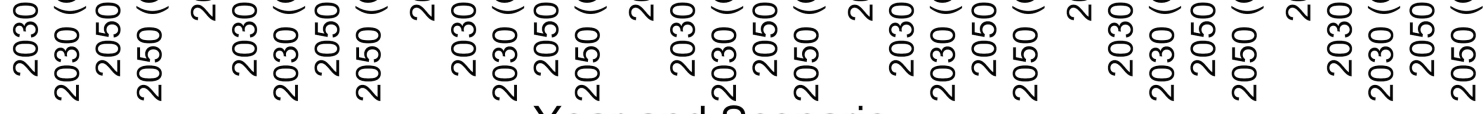
Fuel coal Liquids Natural gas Electricity Hydrogen 


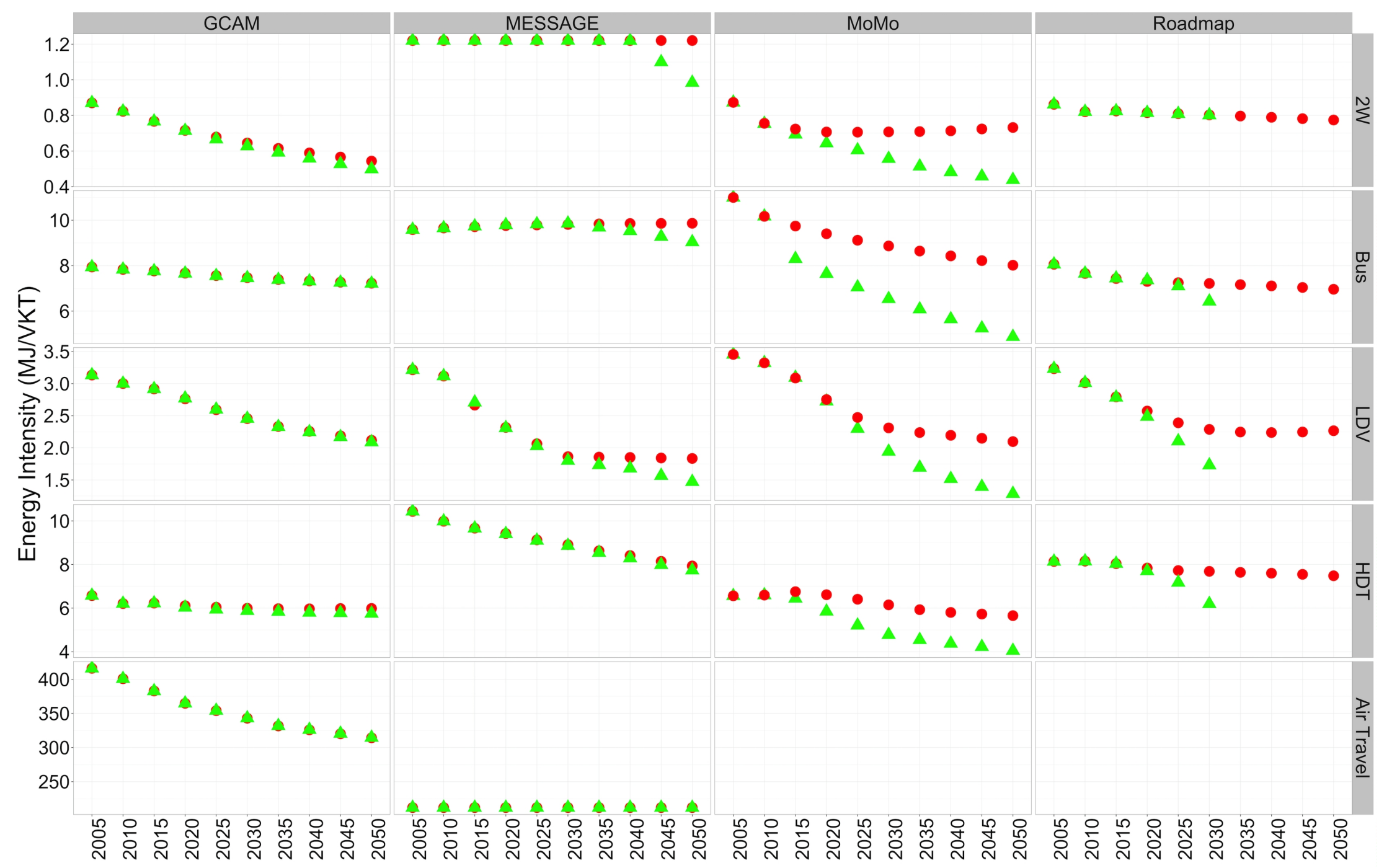

Scenario 


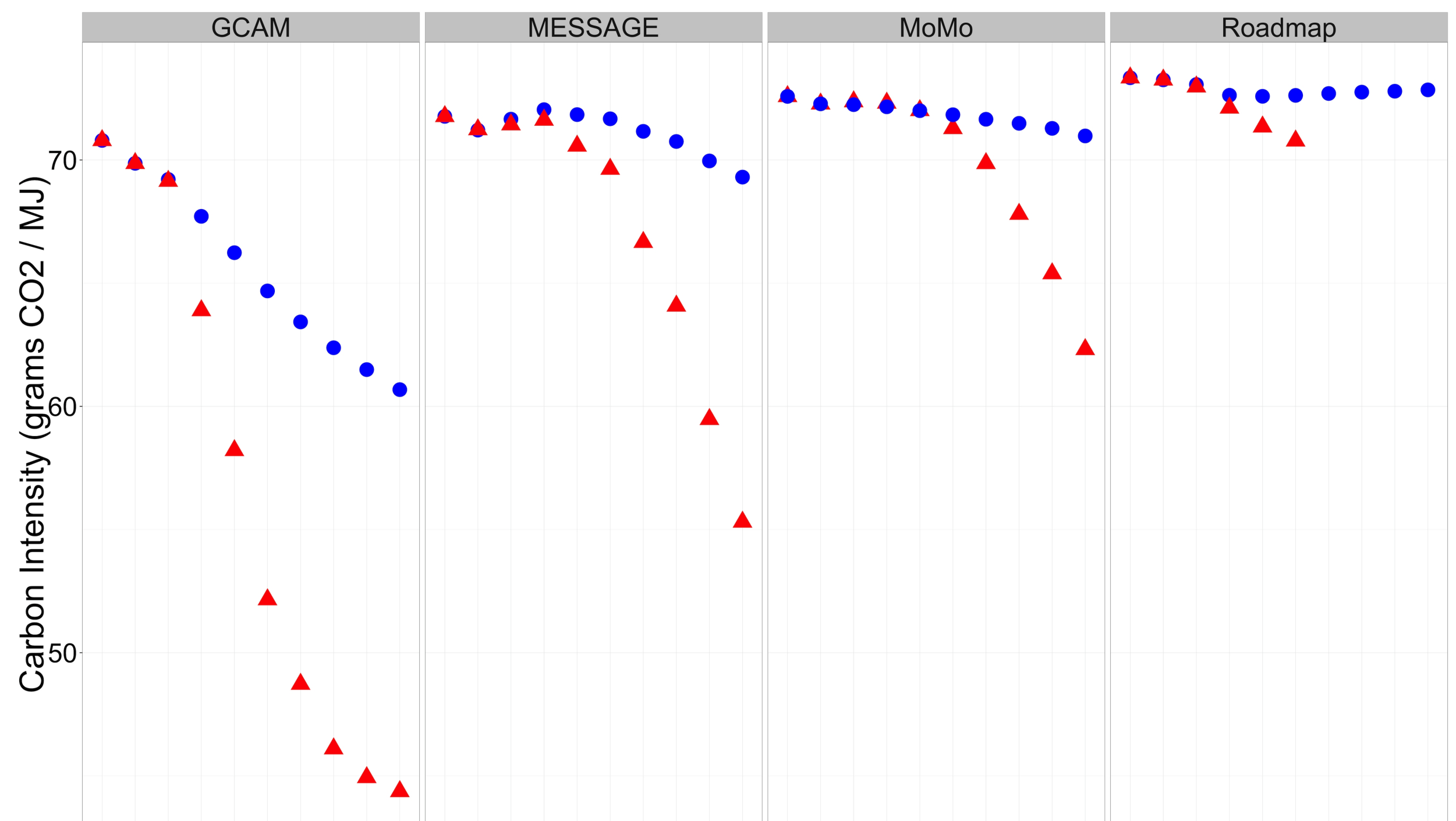

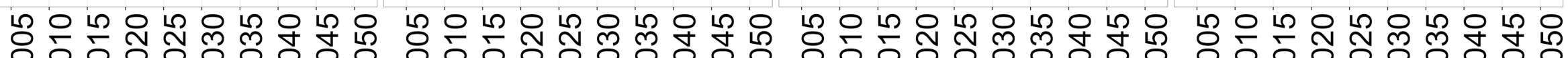

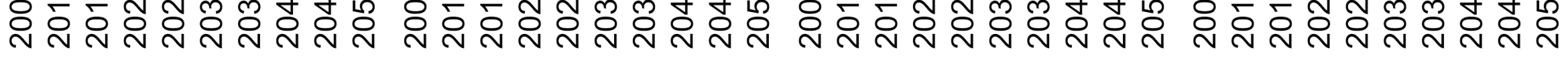



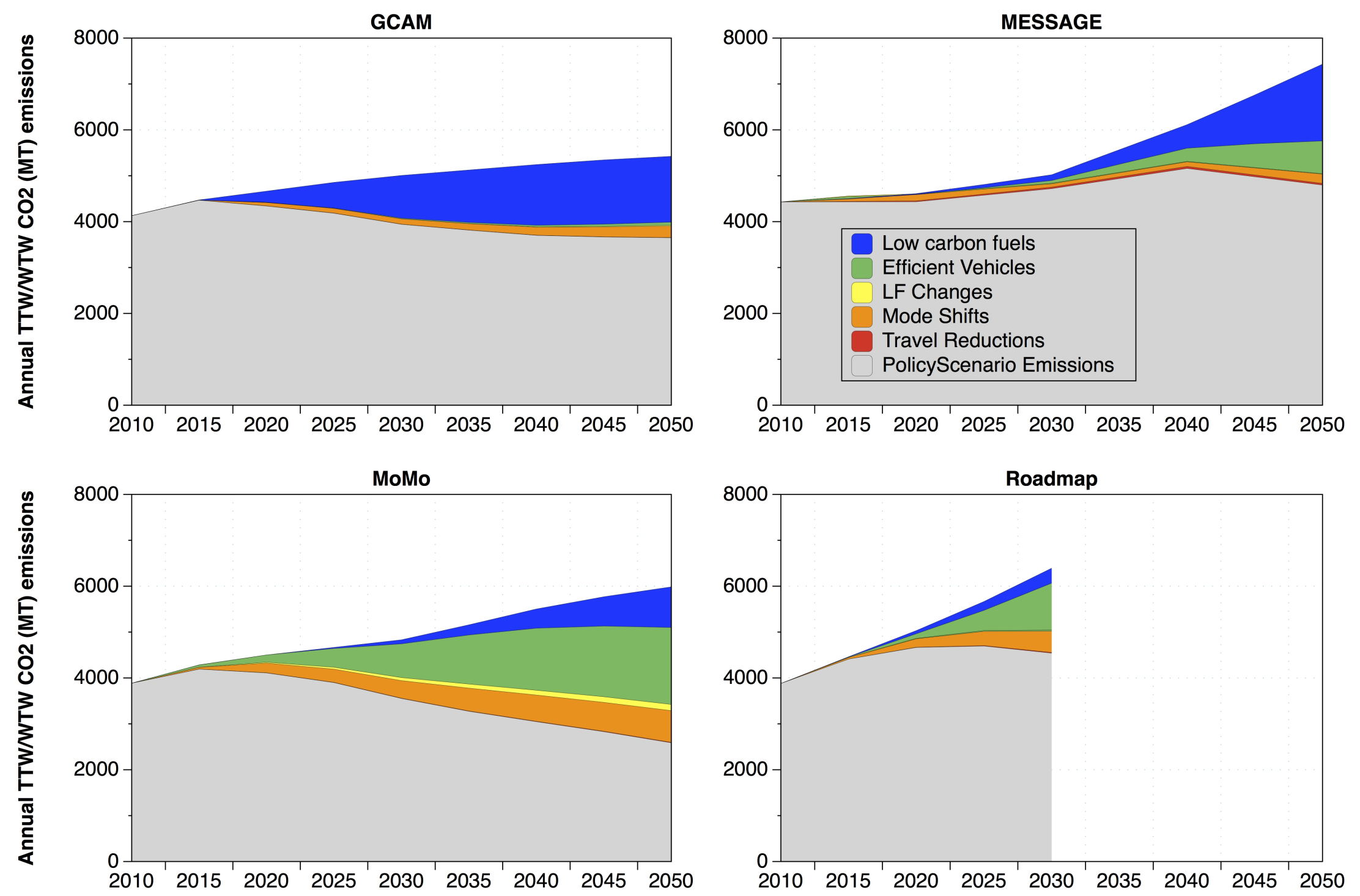


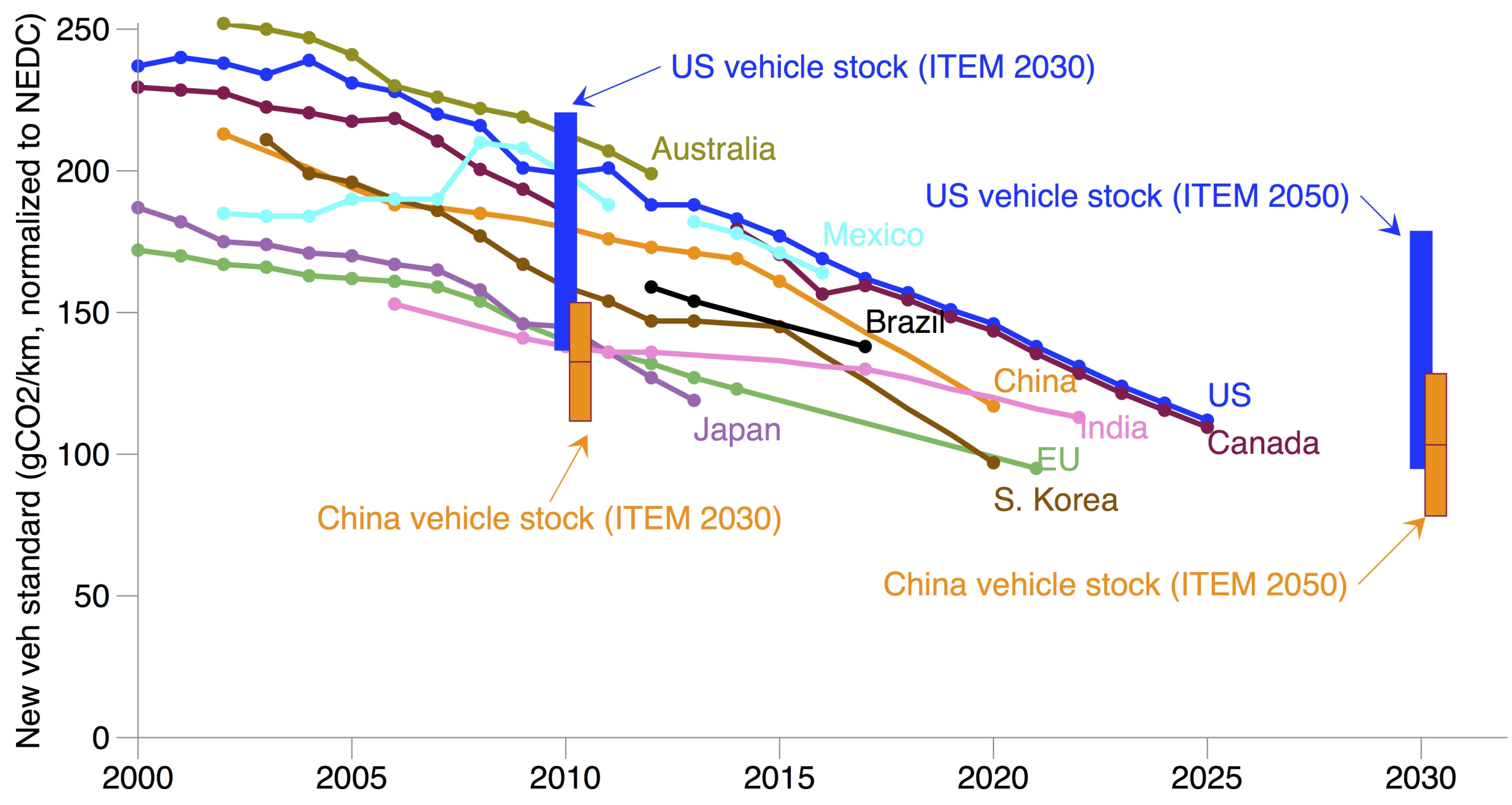


(Big) Data

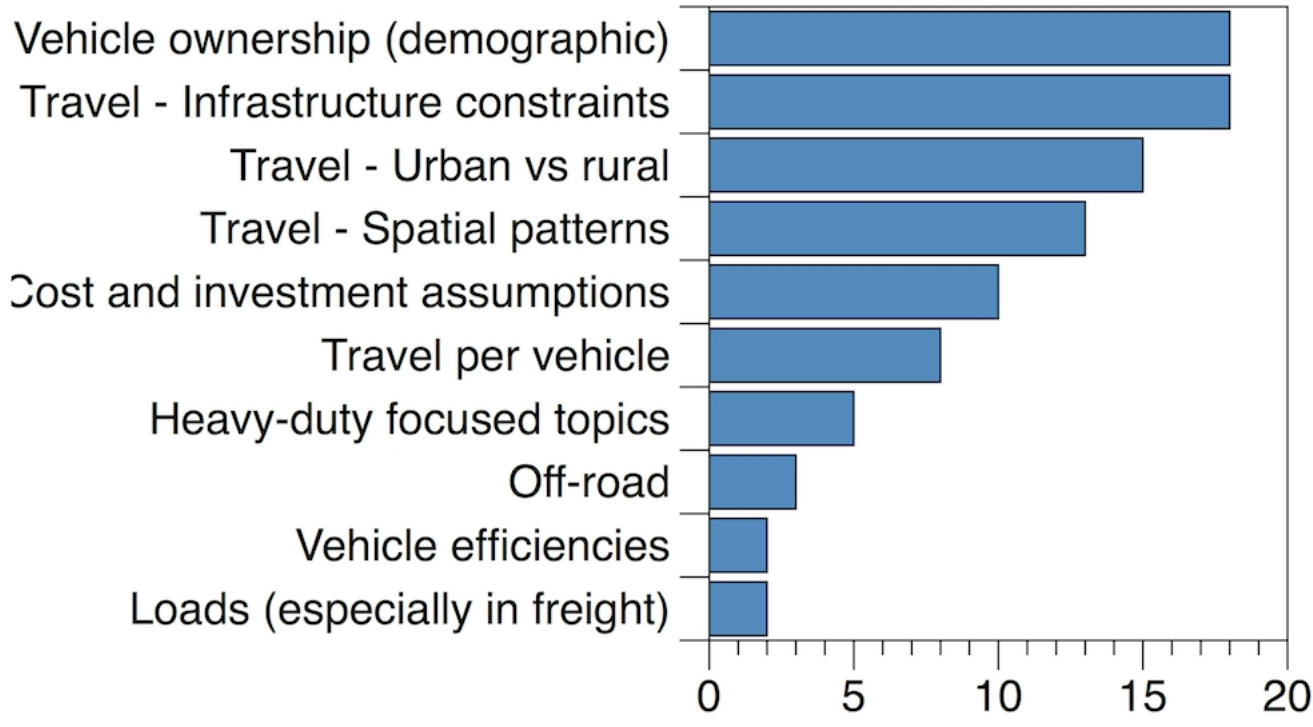

Model Improvement

Policy shifts affecting behaviors

Urban vs rural

Supply constraints (resources)

Behavioral/structural shifts

Freight activities/technology shift

Demographic classes

Modal shift analysis

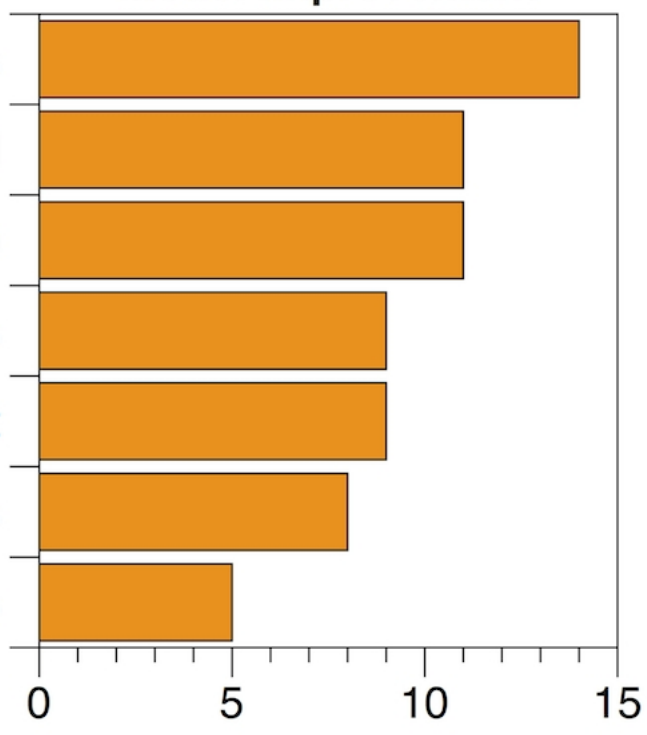

Model Comparison

Alignment on input assumptions

Coordination on historical data

Policy shifts affecting behaviors

Indicator (ratio to GDP, pop, etc)

Modeling approaches

Effects of policy

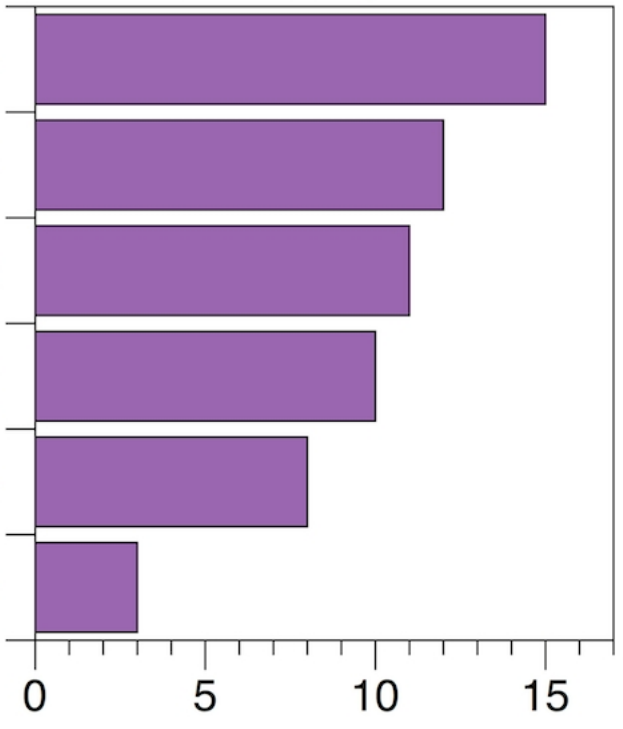


Table 1. Comparison of exogenous and endogenous variables used in the models.

\begin{tabular}{|c|c|c|c|c|}
\hline & \multicolumn{2}{|c|}{ Integrated Assessment Model } & \multicolumn{2}{|c|}{ Transportation Model } \\
\hline & GCAM & MESSAGE & MoMo & RoadMap \\
\hline \multicolumn{5}{|c|}{ Socioeconomic Factors and Demand Drivers } \\
\hline GDP & Ex & Ex & Ex & Ex \\
\hline Population & Ex & Ex & Ex & Ex \\
\hline $\begin{array}{l}\text { Passenger service } \\
\text { demand }\end{array}$ & En & En & En & En \\
\hline Freight service demand & En & En & En & En \\
\hline Mode share & En & En & Ex & Ex \\
\hline \multicolumn{5}{|c|}{ Fuels and Vehicle Technologies } \\
\hline Fuel prices & En & En & Ex & Ex \\
\hline $\begin{array}{l}\text { Energy intensity of fuel } \\
\text { production }\end{array}$ & En & En & Ex & Ex \\
\hline $\begin{array}{l}\text { Shares of fuel types } \\
\text { within modes }\end{array}$ & En & En & Ex & Ex \\
\hline $\begin{array}{l}\text { Efficiency levels of } \\
\text { individual technologies }\end{array}$ & Ex & Ex & Ex & Ex \\
\hline $\begin{array}{l}\text { Efficiency levels within } \\
\text { service, mode, fuel type }\end{array}$ & En & En & En & En \\
\hline \multicolumn{5}{|l|}{ Consumer Behaviors } \\
\hline Average transit speed & Ex & Ex & n.c & n.c \\
\hline $\begin{array}{l}\text { Time cost (mode } \\
\text { choice) }\end{array}$ & $\begin{array}{l}\text { Using wage rate and } \\
\text { mode-specific value } \\
\text { of travel time (VTT) } \\
\text { multipliers to } \\
\text { determine the value } \\
\text { of time in each } \\
\text { mode }\end{array}$ & $\begin{array}{l}\text { Using wage rate and } \\
\text { mode-specific value } \\
\text { of travel time (VTT) } \\
\text { multipliers to } \\
\text { determine the value } \\
\text { of time in each } \\
\text { mode. Also include } \\
\text { travel time and } \\
\text { budget constraints. }\end{array}$ & n.c & n.c \\
\hline
\end{tabular}

Notes: En: Endogenous, results are calculated by the models or by authors based on exogenous drivers; Ex:

Exogenous, values taken directly from external sources; n.c.: Not considered 
Table 2. Comparison of announced policy targets with model-projected number of electric vehicles needed to be on the road by 2020/2025 in order for the transportation sector to be consistent with the $2{ }^{\circ} \mathrm{C}$ target. Average values across models are shown; full ranges in parentheses.

\begin{tabular}{lccc} 
& China & U.S. & Global \\
\hline iTEM & 28 million & 29 million & 113 million \\
& $(2-47)$ & $(9-42)$ & $(35-180)$ \\
Policy/Target & 5 million by 2020* & 1 million EVs by $2015^{+}$ & 20 million by 2020, 100 \\
& & 3.3 million by $2025^{++}$ & million in 2030 \\
\hline
\end{tabular}

\footnotetext{
* Indus. Dev. Strat. Plan (Tan et al. 2014);

+ President's pledge (https://www.whitehouse.gov/sites/default/files/other/fact-sheet-one-million-advancedtechnology-vehicles.pdf);

${ }^{++}$MOU, 8 states (http://www.arb.ca.gov/newsrel/newsrelease.php?id=620);

\# IEA Electric Vehicles Initiative (EVI)

(http://www.iea.org/topics/transport/subtopics/electricvehiclesinitiative/).
} 


\title{
Detailed Assessment of Global Transport-Energy Models' Structures and Projections
}

\section{Supporting Information}

\author{
Sonia Yeh ${ }^{1,2}$, Gouri Shankar Mishra, ${ }^{1,3}$, Lew Fulton ${ }^{1}$, Page Kyle ${ }^{4}$, David L. McCollum ${ }^{5,6}$, Joshua \\ Miller ${ }^{7}$, Pierpaolo Cazzola ${ }^{8}$, Jacob Teter ${ }^{8}$ \\ ${ }^{1}$ Institute of Transportation Studies, University of California, Davis, USA. \\ ${ }^{2}$ Department of Energy and Environment, Chalmers University of Technology, Sweden. \\ ${ }^{3}$ Precourt Energy Efficiency Center, Stanford University, USA. \\ ${ }^{4}$ Joint Global Change Research Institute, Pacific Northwest National Laboratory, USA. \\ ${ }^{5}$ Energy Program, International Institute for Applied Systems Analysis, Austria. \\ ${ }^{6}$ Howard H. Baker Jr. Center for Public Policy, University of Tennessee, USA. \\ ${ }^{7}$ International Council on Clean Transportation, USA. \\ ${ }^{8}$ International Energy Agency, France.
}

\section{Tables}

Table S 1. Basic comparison of model system boundary, resolution, and structure .......................2

Table S 2. Detailed comparison of how key results are projected: demand ...................................

Table S 3. Detailed comparison of how key results are projected: vehicles and fuels technology ..6

Table S 4. Detailed comparison of mechanisms of policy analysis

\section{Figures}

Figure S 1. Accounting system for biofuel $\mathrm{CO}_{2} \mathrm{e}$ emissions

Figure S 2. Estimates of global fuel consumption in 2010 by the transportation sector

Figure S 3. Estimates of global fuel consumption and $\mathrm{TTW} \mathrm{CO}_{2}$ emissions in 2010 disaggregated

by mode .12

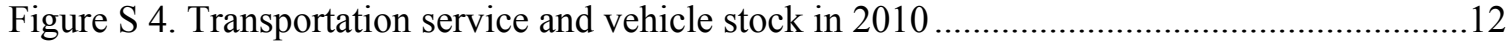

Figure S 5. Assumed annual average VKT for two-wheelers and cars \& light trucks in $2010 \ldots . . .13$

Figure S 6. Projections of annual passenger mobility growth across the Models - Baseline Scenario.

Figure S 7. Per capita vehicle ownership globally and in a few key regions - Baseline Scenario (2010-2050)

Figure S 8. Global stock of cars and light trucks and two-wheelers - Baseline Scenario (20102050)

Figure S 9. Per capita mobility in Baseline and Climate Policy scenarios....

Figure S 10. Stock of car \& light truck (LT) and two-wheelers in Baseline and Climate Policy scenarios.

Figure S 11. Average energy intensity of car and light truck (LT) (MJ/VKT) in Baseline and Policy scenarios.

\section{Appendix}

SI A. Methods for decomposition analysis 
Table S 1. Basic comparison of model system boundary, resolution, and structure

\begin{tabular}{|c|c|c|c|c|}
\hline & GCAM & MESSAGE & MoМo & RoadMap \\
\hline \# of Regions & 32 countries / regions & 11 regions & 33 countries / regions & 16 countries / regions \\
\hline Sectors covered & $\begin{array}{l}\text { Transportation is part of an IAM } \\
\text { that includes all energy sectors } \\
\text { plus land use, forestry, } \\
\text { agriculture, and a simple climate } \\
\text { model. }\end{array}$ & $\begin{array}{l}\text { Transportation is part of an IAM that } \\
\text { includes all energy sectors plus land } \\
\text { use, forestry, agriculture, a simple } \\
\text { climate model, and an aggregated } \\
\text { model of the global macro-economy. }\end{array}$ & Transportation only & Transportation only \\
\hline $\begin{array}{l}\text { Solution } \\
\text { mechanism }\end{array}$ & $\begin{array}{l}\text { Partial equilibrium simulation } \\
\text { based model. The model solution } \\
\text { is based on solving for the set of } \\
\text { prices that brings supplies and } \\
\text { demands into equilibrium in } \\
\text { each market in a recursive / } \\
\text { iterative process. Markets } \\
\text { include energy, agriculture and } \\
\text { other land uses, and emissions } \\
\text { markets. }\end{array}$ & $\begin{array}{l}\text { Systems-engineering optimization } \\
\text { model combined with a macro- } \\
\text { economic model; also includes a logit } \\
\text { function solving for passenger mode } \\
\text { choice in the transport sector } \\
\text { (simulation mode). }\end{array}$ & $\begin{array}{l}\text { "What-if" style accounting and } \\
\text { simulation model based on the } \\
\text { "ASIF" (activity/ structure/ } \\
\text { intensity/ fuel) identity. } \\
\text { Projections are either based on the } \\
\text { separate IEA ETP models or } \\
\text { developed as backcasts to reach a } \\
\text { specific target. The model contains } \\
\text { two elasticities (income and fuel } \\
\text { cost) that can be used for } \\
\text { income/price-related analysis. }\end{array}$ & $\begin{array}{l}\text { The model is a "what-if" } \\
\text { style accounting model } \\
\text { based on the "ASIF" } \\
\text { (activity/ structure/ } \\
\text { intensity/ fuel) identity. }\end{array}$ \\
\hline $\begin{array}{l}\text { System } \\
\text { boundary of } \\
\text { energy and } \\
\text { GHG } \\
\text { accounting }\end{array}$ & $\begin{array}{l}\text { The full fuel cycle of each fuel is } \\
\text { represented, from primary } \\
\text { energy production and } \\
\text { transformation to delivery to the } \\
\text { transportation sector. This } \\
\text { includes biomass from an } \\
\text { agriculture and land use model. } \\
\text { No other upstream inputs to the } \\
\text { sector are considered (e.g. } \\
\text { vehicle manufacturing, roads). } \\
\text { Transportation in GCAM does } \\
\text { not include pipeline energy use, } \\
\text { or infrastructural energy used } \\
\text { (e.g. airport operations, highway } \\
\text { construction and maintenance). }\end{array}$ & $\begin{array}{l}\text { All GHG-emitting and energy } \\
\text { producing/consuming sectors are } \\
\text { included. This implies that indirect } \\
\text { (i.e., lifecycle) energy use and } \\
\text { emissions from fuel production and } \\
\text { vehicle manufacture are included, but } \\
\text { the latter (vehicle manufacture) is not } \\
\text { represented by a direct/endogenous } \\
\text { linkage, rather only through the } \\
\text { assumed future energy demands in } \\
\text { the industrial sector. }\end{array}$ & $\begin{array}{l}\text { The model tracks TTW and } \\
\text { upstream energy/emissions using } \\
\text { simplified fuel cycle assumptions. } \\
\text { In the ETP context, the model } \\
\text { provides fuel demands to the } \\
\text { system, that return supply data } \\
\text { such as electricity and other fuel } \\
\text { feedstock shares, net WTW } \\
\text { emissions, and other inputs to } \\
\text { MoMo. In stand-alone mode (as } \\
\text { used in this comparison project), } \\
\text { such inputs are treated as } \\
\text { exogenous assumptions. }\end{array}$ & $\begin{array}{l}\text { Besides fuel combustion } \\
\text { emissions, the Roadmap } \\
\text { model includes upstream } \\
\text { (well-to-tank) emissions } \\
\text { for fuels (conventional } \\
\text { fuels, electricity, } \\
\text { hydrogen, etc.), and } \\
\text { indirect land use change } \\
\text { for biofuels, but excludes } \\
\text { lifecycle impacts of } \\
\text { vehicle manufacture and } \\
\text { end-of-life. }\end{array}$ \\
\hline $\begin{array}{l}\text { Modes of } \\
\text { passenger }\end{array}$ & $\begin{array}{l}\text { Walking, bicycle, bus, rail, car, } \\
\text { truck, two-wheelers (different }\end{array}$ & $\begin{array}{l}\text { Light-duty vehicles (cars and trucks), } \\
\text { bus, rail (high-speed train, regional }\end{array}$ & $\begin{array}{l}\text { Light-duty vehicles (cars and } \\
\text { trucks), bus, rail (high-speed train, }\end{array}$ & $\begin{array}{l}\text { 2\&3-wheelers, light-duty } \\
\text { vehicles, buses, passenger }\end{array}$ \\
\hline
\end{tabular}




\begin{tabular}{|c|c|c|c|c|}
\hline travel & $\begin{array}{l}\text { size classes in some regions), } \\
\text { three-wheelers (in selected } \\
\text { regions), and air (split into short- } \\
\text { distance and long-distance). }\end{array}$ & $\begin{array}{l}\text { train, tram, metro), two-wheelers, } \\
\text { airplanes. }\end{array}$ & $\begin{array}{l}\text { regional train, tram, metro), two- } \\
\text { and three-wheelers, airplanes. }\end{array}$ & $\begin{array}{l}\text { rail, passenger aircraft. } \\
\text { (excludes off-road). }\end{array}$ \\
\hline $\begin{array}{l}\text { Modes of } \\
\text { freight } \\
\text { transportation }\end{array}$ & $\begin{array}{l}\text { Trucks, freight rail, freight air, } \\
\text { international shipping, and } \\
\text { domestic shipping by inland } \\
\text { waterways. }\end{array}$ & $\begin{array}{l}\text { Trucks, freight rail, freight air, } \\
\text { international shipping, and domestic } \\
\text { shipping by inland waterways. }\end{array}$ & $\begin{array}{l}\text { Trucks, freight rail, freight air, } \\
\text { international shipping, and } \\
\text { domestic shipping by inland } \\
\text { waterways. }\end{array}$ & $\begin{array}{l}\text { Light-, medium-, and } \\
\text { heavy-duty trucks, freight } \\
\text { rail, and freight } \\
\text { waterborne vessels } \\
\text { (domestic and } \\
\text { international). Excludes } \\
\text { pipelines, three-wheeled } \\
\text { freight vehicles, and off- } \\
\text { road. }\end{array}$ \\
\hline Infrastructure & Not explicitly modeled & Not explicitly modeled & $\begin{array}{l}\text { Infrastructure (road/rail length, } \\
\text { parking space, etc.) required to } \\
\text { accommodate traffic growth are } \\
\text { estimated and tracked in the } \\
\text { model. }\end{array}$ & Not explicitly modeled \\
\hline $\begin{array}{l}\text { Other modelled } \\
\text { elements }\end{array}$ & & & $\begin{array}{l}\text { Vehicle production-related } \\
\text { materials and emissions; upstream } \\
\text { fuel production-related emissions. }\end{array}$ & $\begin{array}{l}\text { Criteria pollutants } \\
\text { emissions as a function of } \\
\text { vehicle age, emission } \\
\text { control technology, and } \\
\text { travel patterns. }\end{array}$ \\
\hline
\end{tabular}


Table S 2. Detailed comparison of how key results are projected: demand

\begin{tabular}{|c|c|c|c|c|}
\hline & GCAM & MESSAGE & МoМo & RoadMap \\
\hline $\begin{array}{l}\text { Passenger } \\
\text { travel } \\
\text { service } \\
\text { demand }\end{array}$ & $\begin{array}{l}\text { Demand for any given year is } \mathrm{D}_{\mathrm{t}}= \\
\mathrm{D}_{\mathrm{t}-1} * \text { GDP_Ratio Inc_Elas } * \\
\text { Price_Ratio } \\
\text { Whice_Elas, } \\
\text { base year (2010). Price includes the } \\
\text { time value of transportation, which } \\
\text { increases with the wage rate. So as } \\
\text { income increases, at low levels the } \\
\text { effective income elasticity is } 1 \\
\text { whereas at higher levels it is about } \\
0.1 . \text { All regions are assigned constant } \\
\text { income and price elasticities in all } \\
\text { time periods. }\end{array}$ & $\begin{array}{l}\text { Passenger demands are estimated } \\
\text { based on income (GDP/capita), } \\
\text { population, and total cost of travel } \\
\text { across modes that are responsive } \\
\text { to price changes. Total passenger } \\
\text { transport demand (aggregate of all } \\
\text { modes) moves toward a saturation } \\
\text { point (at the highest incomes } \\
\text { reached in the very long term) of } \\
150,000 \mathrm{pkm} / \mathrm{yr} \text {. }\end{array}$ & $\begin{array}{l}\text { For private vehicles (cars/2- } \\
\text { wheelers), ownership is function } \\
\text { of income, calibrated to different } \\
\text { countries and regions based on } \\
\text { saturation rates observed in richer } \\
\text { countries in the same region. A } \\
\text { Gompertz function is used to fit } \\
\text { ownership curves. For public } \\
\text { modes (rail/bus), a time trend is } \\
\text { used based on trends over the } \\
\text { past } 10 \text { years. Air and shipping } \\
\text { are based on calibration to other } \\
\text { published projects (e.g. IATA, } \\
\text { IMO). Overall these different } \\
\text { activity projections are then } \\
\text { calibrated to the IEA WEO model } \\
\text { and adjusted to help ensure that } \\
\text { energy use is consistent to } 2035 \text {. }\end{array}$ & $\begin{array}{l}\text { Passenger transportation } \\
\text { activity (pkm) are projected } \\
\text { based on exogenous changes in } \\
\text { GDP, population, and fuel } \\
\text { prices. Relationships between } \\
\text { socio-economic indicators and } \\
\text { transport activity are derived } \\
\text { from regression analyses of } \\
\text { vehicles/capita and mode } \\
\text { shares based on per-capita GDP } \\
\text { (passenger modes). }\end{array}$ \\
\hline $\begin{array}{l}\text { Passenger } \\
\text { transport } \\
\text { mode } \\
\text { choice }\end{array}$ & $\begin{array}{l}\text { Changes to shares are endogenous, } \\
\text { based on the total service costs of } \\
\text { each competing mode, which } \\
\text { includes the time value of } \\
\text { transportation over time. }\end{array}$ & $\begin{array}{l}\text { Modes compete with each other } \\
\text { based on the average cost of travel } \\
(\$ / \mathrm{PKT}) \text { for each mode, which is } \\
\text { based on cost of technology } \\
\text { (based on fuel and vehicle cost } \\
\text { and load factor) and cost of } \\
\text { people's time (based on wage rate } \\
\text { and travel speed) subject to } \\
\text { constraints on travel time and } \\
\text { money budgets. Thus, there is a } \\
\text { tendency to migrate to faster } \\
\text { modes as income grows. }\end{array}$ & $\begin{array}{l}\text { Thus there is no mode-share- } \\
\text { based system for allocating travel } \\
\text { when establishing a reference } \\
\text { case. However, there is a modal } \\
\text { shift analysis capability in the } \\
\text { model whereby travel can be } \\
\text { shifted from one mode to another } \\
\text { (or multiple modes) in a manner } \\
\text { that preserves the reference case } \\
\text { total travel (or allows this also to } \\
\text { change). This mode-shift analysis } \\
\text { system is also used in a "what-if" } \\
\text { capacity. } 1\end{array}$ & $\begin{array}{l}\text { Relationships between socio- } \\
\text { economic indicators and mode- } \\
\text { specific transport activity are } \\
\text { derived from regression } \\
\text { analyses of mode shares based } \\
\text { on per-capita GDP (passenger } \\
\text { modes). Mode-switching is an } \\
\text { exogenous policy lever. }\end{array}$ \\
\hline
\end{tabular}

${ }^{1}$ For example, one can check the effects of putting bus-rapid-transit systems in cities around the world, projecting ridership on these systems, assuming shifts to BRT from other modes, and then tracking the overall passenger travel changes by mode and the subsequent impacts of fuel use and $\mathrm{CO}_{2} \mathrm{emissions}$ 


\begin{tabular}{|c|c|c|c|c|}
\hline $\begin{array}{l}\text { Passenger } \\
\text { transport } \\
\text { technology }\end{array}$ & $\begin{array}{l}\text { Within each mode, model selects } \\
\text { mixes of technology based on the } \\
\text { nested logit functions, but with an } \\
\text { exogenous parameter for } \\
\text { uncalibrated technologies using the } \\
\text { "shareweight" in the logit equation }\end{array}$ & $\begin{array}{l}\text { Within each mode, model selects } \\
\text { mixes of technology by } \\
\text { minimizing costs of fuel and } \\
\text { vehicle (investment and O\&M) } \\
\text { costs, vehicle occupancy rates, } \\
\text { and annual distance traveled per } \\
\text { vehicle }\end{array}$ & $\begin{array}{l}\text { Based on expert judgment or } \\
\text { what-if analysis, as well as } \\
\text { backcast technique for policy } \\
\text { analysis. Overall these different } \\
\text { activity projections are then } \\
\text { calibrated to the IEA WEO model } \\
\text { and adjusted to help ensure that } \\
\text { energy use is consistent to } 2035 \text {. }\end{array}$ & $\begin{array}{l}\text { Based on expert judgment or } \\
\text { what-if analysis, as well as } \\
\text { backcast technique for policy } \\
\text { analysis. }\end{array}$ \\
\hline $\begin{array}{l}\text { Freight } \\
\text { transport } \\
\text { demand }\end{array}$ & $\begin{array}{l}\text { Energy demand trajectory is } \\
\text { estimated based on population and } \\
\text { GDP that is subject to price-induced } \\
\text { demand response. }\end{array}$ & $\begin{array}{l}\text { Energy demand trajectory is } \\
\text { estimated based on population and } \\
\text { GDP that is subject to price- } \\
\text { induced demand response in an } \\
\text { aggregated macro-economic } \\
\text { model (MACRO). }\end{array}$ & $\begin{array}{l}\text { Energy demand trajectory is } \\
\text { estimated based on population } \\
\text { and GDP }\end{array}$ & $\begin{array}{l}\text { Freight transportation activity } \\
\text { (tonne-km) are projected based } \\
\text { on exogenous changes in GDP, } \\
\text { population, and fuel prices. } \\
\text { Relationships between socio- } \\
\text { economic indicators and } \\
\text { transport activity are derived } \\
\text { from regression analyses of } \\
\text { freight activity per unit of } \\
\text { economic activity. }\end{array}$ \\
\hline
\end{tabular}


Table S 3. Detailed comparison of how key results are projected: vehicles and fuels technology

\begin{tabular}{|c|c|c|c|c|}
\hline & GCAM & MESSAGE & МoМo & Roadmap \\
\hline \multicolumn{5}{|l|}{ Vehicles } \\
\hline $\begin{array}{l}\text { LDV size } \\
\text { breakdown }\end{array}$ & $\begin{array}{l}\text { Each region gets four size classes, } \\
\text { with the size classes specified } \\
\text { according to the actual } \\
\text { composition of the vehicle fleet in } \\
\text { each region. }\end{array}$ & None & $\begin{array}{l}\text { Light-duty vehicles are disaggregated into } 2 \\
\text { size classes (cars and light trucks). There is } \\
\text { a prototype fuel economy module that } \\
\text { further disaggregates them into } 6 \text { or more } \\
\text { size classes. }\end{array}$ & None \\
\hline $\begin{array}{l}\text { Non-LDV size } \\
\text { breakdown }\end{array}$ & $\begin{array}{l}\text { Bus: disaggregated to size classes } \\
\text { (large and small) in China only. } \\
\text { Trucks of }<1 \mathrm{t}, 1-5 \text { tons, } 5-10 \text { tons, } \\
\text { and greater than } 10 \text { tons }\end{array}$ & None & $\begin{array}{l}\text { Trucks are disaggregated into } 3 \text { size/weight } \\
\text { classes (light/medium/heavy). }\end{array}$ & $\begin{array}{l}\text { LHDT: } 8,501 \text { to } \\
14,000 \mathrm{lbs} \\
\text { MHDT: } 14,001 \text { to } \\
\text { 33,000 lbs } \\
\text { HHDT: } 33,001 \mathrm{lbs} \\
\text { and over. }\end{array}$ \\
\hline $\begin{array}{l}\text { Technology cost } \\
\text { and efficiency } \\
\text { assumptions }\end{array}$ & $\begin{array}{l}\text { The purchase cost and efficiency } \\
\text { of new technology vehicles decline } \\
\text { over time exogenously. }\end{array}$ & $\begin{array}{l}\text { The purchase cost and } \\
\text { efficiency of new technology } \\
\text { vehicles generally decline over } \\
\text { time exogenously. }\end{array}$ & $\begin{array}{l}\text { The purchase cost of new technology } \\
\text { vehicles decline over time as a (off-line } \\
\text { calculated) function of time, scale and } \\
\text { learning (learning itself a function of } \\
\text { cumulative sales over time). Efficiencies } \\
\text { improve as a function of technology uptake, } \\
\text { handled incrementally and in some detail } \\
\text { for conventional cars and light trucks. } \\
\text { These become more expensive over time as } \\
\text { more efficiency technologies are added - } \\
\text { for those scenarios where this occurs. }\end{array}$ & $\begin{array}{l}\text { Transport } \\
\text { efficiencies are } \\
\text { specified } \\
\text { exogenously based } \\
\text { on data sources and } \\
\text { regulations }\end{array}$ \\
\hline $\begin{array}{l}\text { Competition } \\
\text { between vehicle } \\
\text { technologies } \\
\text { (including } \\
\text { penetration of } \\
\text { alternative fuel } \\
\text { vehicles (AFVs)) }\end{array}$ & $\begin{array}{l}\text { All competition is based on logit } \\
\text { sharing, where the shares are } \\
\text { allocated based on average } \\
\text { levelized costs of service } \\
\text { provision. This competition is } \\
\text { influenced by an exogenous } \\
\text { "share-weight" parameter, which } \\
\text { modifies the share allocated to the } \\
\text { different options at any given price } \\
\text { level. The competition is }\end{array}$ & $\begin{array}{l}\text { Least-cost optimization based } \\
\text { on discounted net present cost } \\
\text { of each technology at each } \\
\text { point in time (including vehicle } \\
\text { investment costs, fixed and } \\
\text { variable O\&M costs, and fuel } \\
\text { costs). }\end{array}$ & $\begin{array}{l}\text { Based on expert judgment or what-if } \\
\text { analysis, as well as backcast technique. For } \\
\text { example, most scenarios where large } \\
\text { numbers of electric vehicles penetrate the } \\
\text { fleet are based on reaching a target CO2 } \\
\text { reduction in 2050, and EVs are part of the } \\
\text { scenario to reach this target. There may be } \\
\text { more or fewer EVs depending the specifics } \\
\text { of the scenario, the assumed future cost and } \\
\text { range of EVs, etc. But none of this is }\end{array}$ & $\begin{array}{l}\text { Base on expert } \\
\text { judgement or what- } \\
\text { if analysis, as well } \\
\text { as backcast } \\
\text { analysis. }\end{array}$ \\
\hline
\end{tabular}




\begin{tabular}{|c|c|c|c|c|}
\hline & $\begin{array}{l}\text { endogenous, driven mostly by fuel } \\
\text { prices and vehicle costs. }\end{array}$ & & calculated endogenously. & \\
\hline Biofuels blend & $\begin{array}{l}\text { Assume perfect substitution with } \\
\text { petroleum-based liquid fuels. }\end{array}$ & $\begin{array}{l}\text { Up to } 100 \% \text { biofuels blends are } \\
\text { possible. There are two types } \\
\text { of full biofuel vehicles: } \\
\text { conventional ICEs and hybrid } \\
\text { ICEs. The model can flexibly } \\
\text { switch between fossil fuel and } \\
\text { biofuel ICEs/HEVs, meaning } \\
\text { that the blend level is simply a } \\
\text { weighted sum of the two } \\
\text { technology/fuel classes. }\end{array}$ & $\begin{array}{l}\text { Ethanol } 10 \% \text { blendwall problems are } \\
\text { overcome by } 2020 \text { and no limit of ethanol } \\
\text { blending after then. Drop-in biofuels play } \\
\text { an increasingly important role after } 2025 \text {. }\end{array}$ & $\begin{array}{l}\text { Biofuel blends are } \\
\text { specified } \\
\text { exogenously based } \\
\text { on data sources and } \\
\text { regulations. }\end{array}$ \\
\hline \multicolumn{5}{|c|}{ 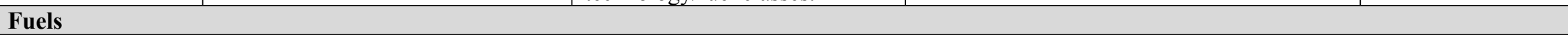 } \\
\hline $\begin{array}{l}\text { Biofuels carbon } \\
\text { emissions }\end{array}$ & $\begin{array}{l}\text { Biomass is treated as carbon } \\
\text { neutral - however upstream } \\
\text { sequestration and tailpipe } \\
\text { emissions are tracked } \\
\text { independently. Land use change } \\
\text { emissions, including fertilizer use, } \\
\text { production, and transportation are } \\
\text { fully captured endogenously (as a } \\
\text { function of yield changes). }\end{array}$ & $\begin{array}{l}\text { Biomass is currently assumed } \\
\text { to be carbon neutral. Feedstock } \\
\text { production incurs no negative } \\
\text { emissions, and biofuels } \\
\text { combustion incurs no positive } \\
\text { emissions. Only second- } \\
\text { generation biofuels are } \\
\text { assumed to be available. }\end{array}$ & $\begin{array}{l}\text { Third party estimates (such as JRC, GREET } \\
\text { studies) of WTW GHG emissions of } \\
\text { different pathways are applied to MoMo } \\
\text { fuel consumption estimates. They do not } \\
\text { include indirect land use change and } \\
\text { typically cite a WTW GHG emissions } \\
\text { reduction for advanced biofuels in the } 70- \\
85 \% \text { range compared to gasoline/diesel. }\end{array}$ & $\begin{array}{l}\text { Upstream emissions } \\
\text { are exogenously } \\
\text { specified. Biofuels } \\
\text { consider indirect } \\
\text { land-use effects; } \\
\text { several upstream } \\
\text { treatment options } \\
\text { are included. }\end{array}$ \\
\hline Fuel costs & $\begin{array}{l}\text { Endogenously determined by } \\
\text { supply sector part of model where } \\
\text { fuel costs are determined by an } \\
\text { exogenous sets of supply curves } \\
\text { and the prices are set when supply } \\
\text { and demand are in equilibrium. }\end{array}$ & $\begin{array}{l}\text { Endogenously determined by } \\
\text { supply sector part of model } \\
\text { where fuel costs are determined } \\
\text { by an exogenous sets of supply } \\
\text { curves and the prices are set } \\
\text { when supply and demand are in } \\
\text { equilibrium. }\end{array}$ & $\begin{array}{l}\text { In the ETP context, the model provides fuel } \\
\text { demands to the supply system as modeled } \\
\text { in ETP-TIMES, which in return provides } \\
\text { supply data such as electricity and other } \\
\text { fuel feedstock shares and prices. In stand- } \\
\text { alone mode (as used in this comparison } \\
\text { project), such inputs are treated as } \\
\text { exogenous assumptions. There is no } \\
\text { feedback between fuel use and fuel prices. }\end{array}$ & $\begin{array}{l}\text { Exogenously } \\
\text { specified. }\end{array}$ \\
\hline Discount rate & $5 \%$ & $5 \%$ & No discounting of future costs & $\mathrm{N} / \mathrm{A}$ \\
\hline
\end{tabular}


Table S 4. Detailed comparison of mechanisms of policy analysis.

\begin{tabular}{|c|c|c|c|c|}
\hline & GCAM & MESSAGE & MoМo & RoadMap \\
\hline \multicolumn{5}{|c|}{ Energy use intensity } \\
\hline $\begin{array}{l}\text { Overall energy } \\
\text { intensity } \\
\text { improvement }\end{array}$ & $\begin{array}{l}\text { Through exogenous assumptions of } \\
\text { vehicle efficiency improvement over time } \\
\text { and endogenously modeling of } \\
\text { fuel/vehicle technology penetration and } \\
\text { mode change. }\end{array}$ & $\begin{array}{l}\text { Through exogenous } \\
\text { assumptions of vehicle } \\
\text { efficiency improvement over } \\
\text { time and endogenous } \\
\text { modeling of fuel/vehicle } \\
\text { technology penetration and } \\
\text { mode change. }\end{array}$ & $\begin{array}{l}\text { Through exogenous } \\
\text { assumptions of vehicle } \\
\text { efficiency improvement over } \\
\text { time and endogenously } \\
\text { modeling of fuel/vehicle } \\
\text { technology penetration and } \\
\text { mode change. }\end{array}$ & $\begin{array}{l}\text { Through exogenous assumptions } \\
\text { of vehicle efficiency } \\
\text { improvement over time and } \\
\text { endogenously modeling of } \\
\text { fuel/vehicle technology } \\
\text { penetration and mode change. }\end{array}$ \\
\hline \multicolumn{5}{|l|}{ Policy modeling } \\
\hline $\begin{array}{l}\text { Energy } \\
\text { efficiency } \\
\text { standards }\end{array}$ & Exogenously constrained & Exogenously constrained & Exogenously constrained & Exogenously constrained \\
\hline $\begin{array}{l}\text { Carbon policy } \\
\text { (e.g. carbon } \\
\text { taxes, cap and } \\
\text { trade) }\end{array}$ & $\begin{array}{l}\text { Economy- and sector-wide carbon taxes } \\
\text { and carbon caps; vehicle- and mode- } \\
\text { specific carbon emission; carbon tax that } \\
\text { include land use change can also be } \\
\text { analyzed. }\end{array}$ & $\begin{array}{l}\text { Economy- and sector-wide } \\
\text { carbon taxes and carbon } \\
\text { caps; vehicle- and mode- } \\
\text { specific carbon emissions }\end{array}$ & $\begin{array}{l}\text { Policies are handled by doing } \\
\text { off-line analysis of the effect } \\
\text { of the policy on one or other } \\
\text { of these levers, then input into } \\
\text { the model. Examples include } \\
\text { fuels and electricity carbon } \\
\text { standards. }\end{array}$ & $\begin{array}{l}\text { Policies are handled by doing } \\
\text { off-line analysis of the affect of } \\
\text { the policy on one or other of } \\
\text { these levers, then input into the } \\
\text { model. Examples include fuels } \\
\text { and electricity carbon standards. }\end{array}$ \\
\hline $\begin{array}{l}\text { Monetary } \\
\text { policy (e.g } \\
\text { subsidies) }\end{array}$ & $\begin{array}{l}\text { Essentially any policy that affects the } \\
\text { levelized cost (discounted net present } \\
\text { value) of supplying energy service } \\
\text { demand by a given technology will by } \\
\text { extension can be modeled endogenously. } \\
\text { Examples include vehicle and fuel } \\
\text { subsidies. }\end{array}$ & $\begin{array}{l}\text { Essentially any policy that } \\
\text { affects the levelized cost } \\
\text { (discounted net present } \\
\text { value) of supplying energy } \\
\text { service demand by a given } \\
\text { technology can, by } \\
\text { extension, be modeled } \\
\text { endogenously. Examples } \\
\text { include vehicle and fuel } \\
\text { subsidies. }\end{array}$ & $\begin{array}{l}\text { Fuel tax policy can be } \\
\text { modeled with fuel cost } \\
\text { elasticity. Higher prices } \\
\text { dampen travel demand while } \\
\text { lower fuel costs trigger a } \\
\text { rebound effect. Other price } \\
\text { policies (such as for AFVs) } \\
\text { handled off-line }\end{array}$ & $\begin{array}{l}\text { Conducted through off-line } \\
\text { analysis. }\end{array}$ \\
\hline Others & $\begin{array}{l}\text { Air pollutant standards. Exogenously } \\
\text { implementation; no economic feedbacks. } \\
\text { Essentially any policy that affects the } \\
\text { levelized cost (discounted net present } \\
\text { value) of supplying energy service }\end{array}$ & $\begin{array}{l}\text { Vehicle sales mandates. } \\
\text { Essentially any policy that } \\
\text { affects the levelized cost } \\
\text { (discounted net present } \\
\text { value) of supplying energy }\end{array}$ & $\begin{array}{l}\text { Policies are handled by doing } \\
\text { off-line analysis of the affect } \\
\text { of the policy on one or other } \\
\text { of these levers, then input into } \\
\text { the model. Policies included }\end{array}$ & $\begin{array}{l}\text { Vehicle conventional pollutant } \\
\text { standards, low-sulfur fuels. } \\
\text { Other policies are handled by } \\
\text { doing off-line analysis of the } \\
\text { affect of the policy on one or }\end{array}$ \\
\hline
\end{tabular}




\begin{tabular}{|l|l|l|l|l|}
\hline & $\begin{array}{l}\text { demand by a given technology will by } \\
\text { extension can be modeled endogenously. } \\
\begin{array}{l}\text { Public transport-related policies: } \\
\text { implemented as increased speeds for } \\
\text { public transit modes, which tends to } \\
\text { increase the shares of these modes. }\end{array}\end{array}$ & $\begin{array}{l}\text { service demand by a given } \\
\text { technology can, by } \\
\text { extension, be modeled } \\
\text { endogenously. }\end{array}$ & $\begin{array}{l}\text { are: introduction of new } \\
\text { vehicle/fuel types, changes in } \\
\text { modal shares, changes in } \\
\text { vehicle ownership patterns. }\end{array}$ & $\begin{array}{l}\text { other of these levers, then input } \\
\text { into the model: examples } \\
\text { include passenger and freight } \\
\text { mode shift, activity reduction / } \\
\text { market-based measures. }\end{array}$ \\
\hline
\end{tabular}


Figure S 1. Accounting system for biofuel $\mathrm{CO}_{2}$ emissions

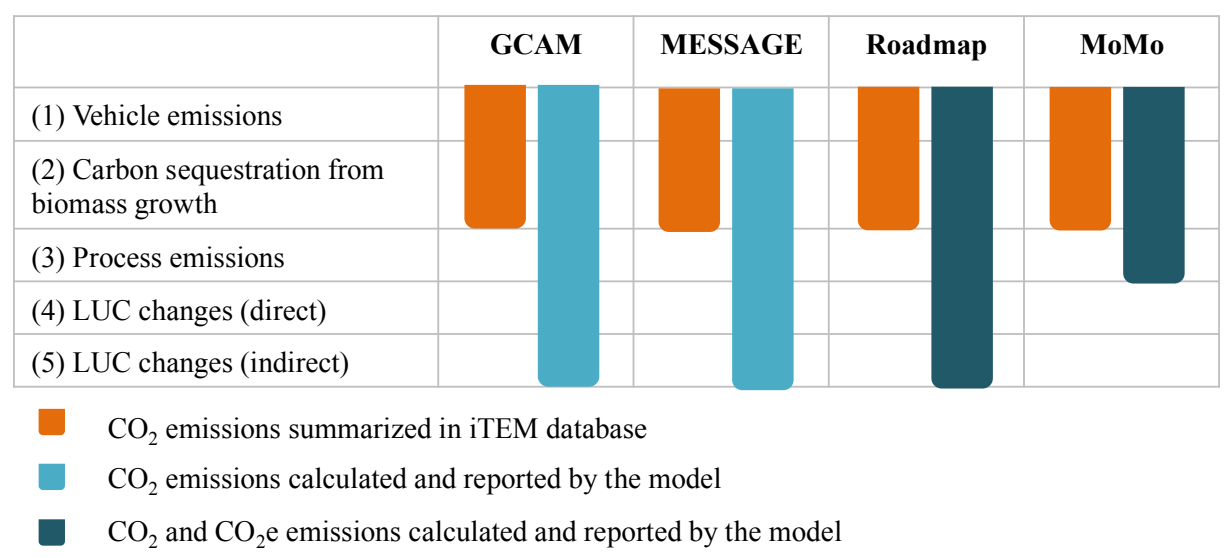

Figure S 2. Estimates of global fuel consumption and TTW $\mathrm{CO}_{2}$ emissions in 2010 disaggregated by mode

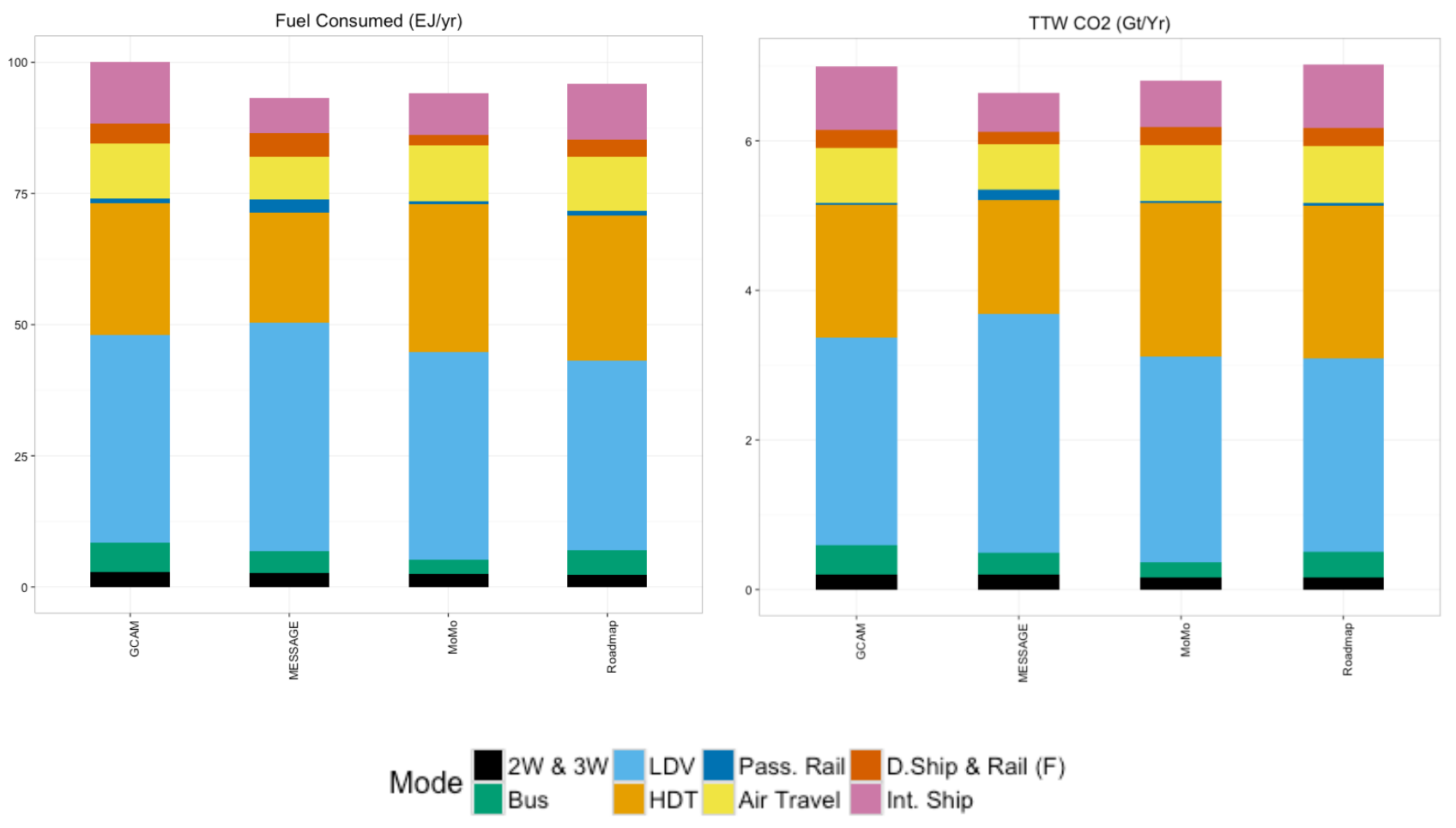


Figure S 3. Transportation service and vehicle stock in 2010

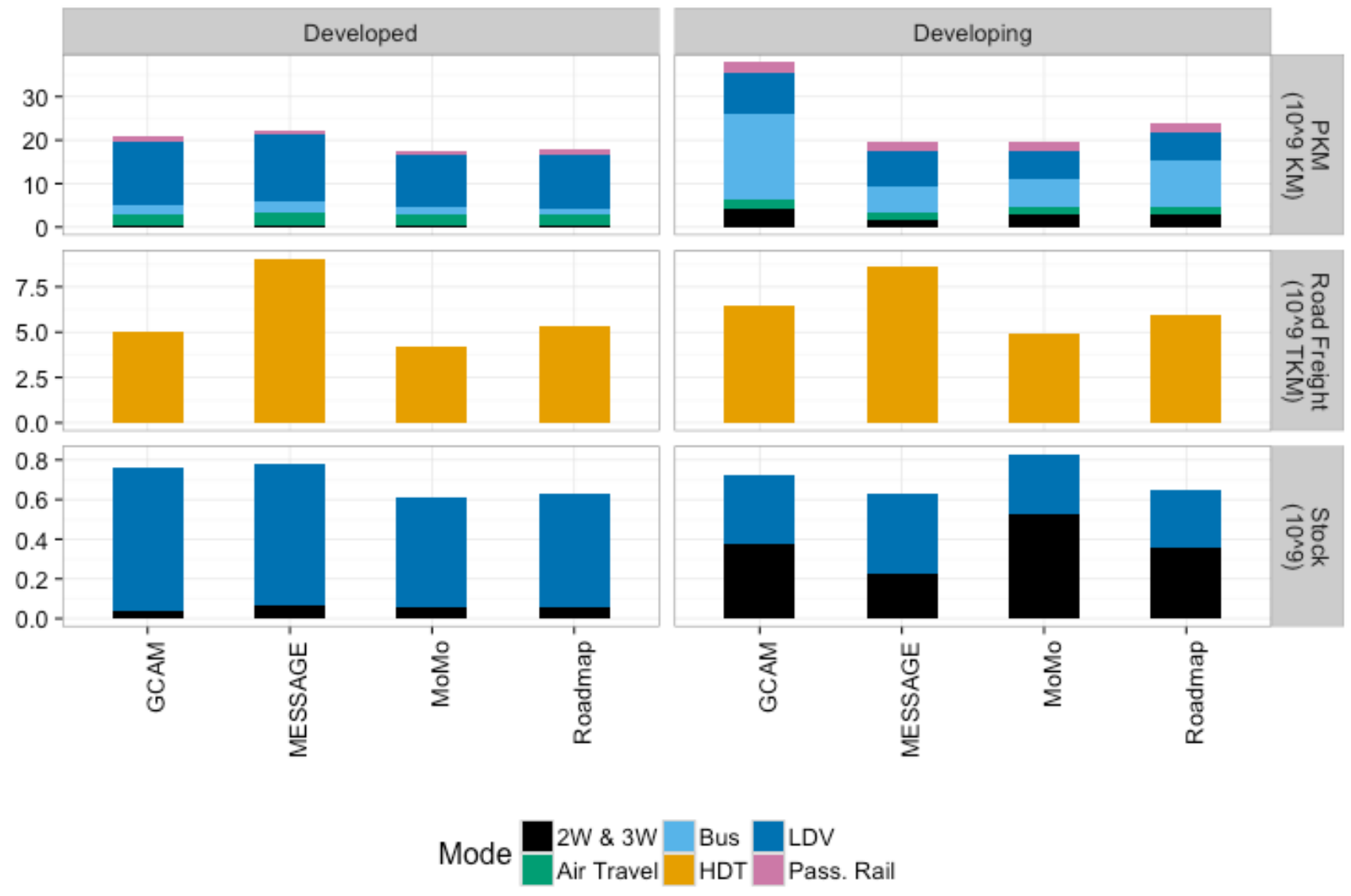


Figure S 4. Assumed annual average VKT for two-wheelers and LDVs (cars \& light trucks) in 2010

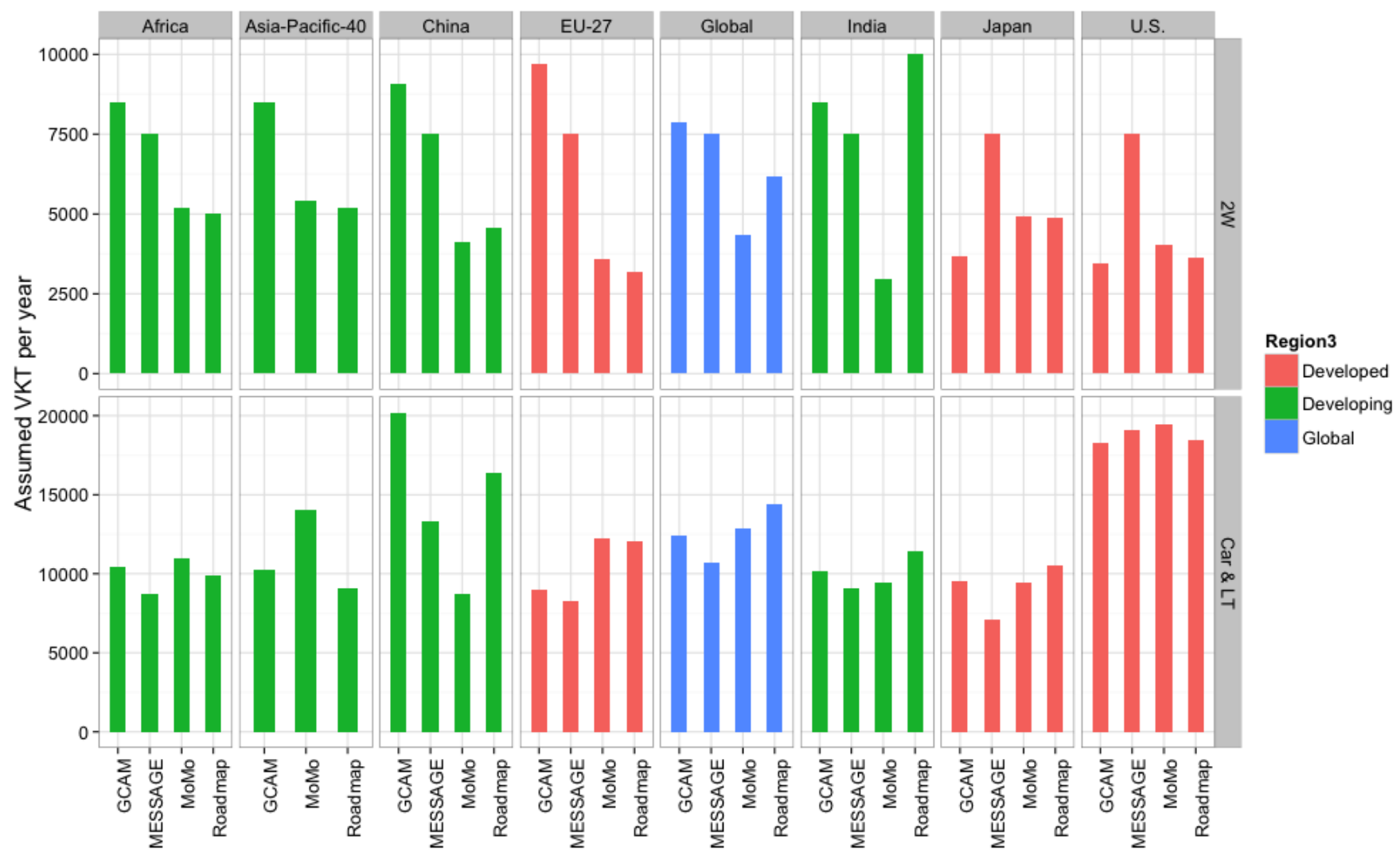

Figure $\mathrm{S}$ 5. Estimates of global fuel consumption in 2010, 2030 and 2050 by the transportation sector. (B) represents baseline scenario and (CP) represents climate policy scenario.
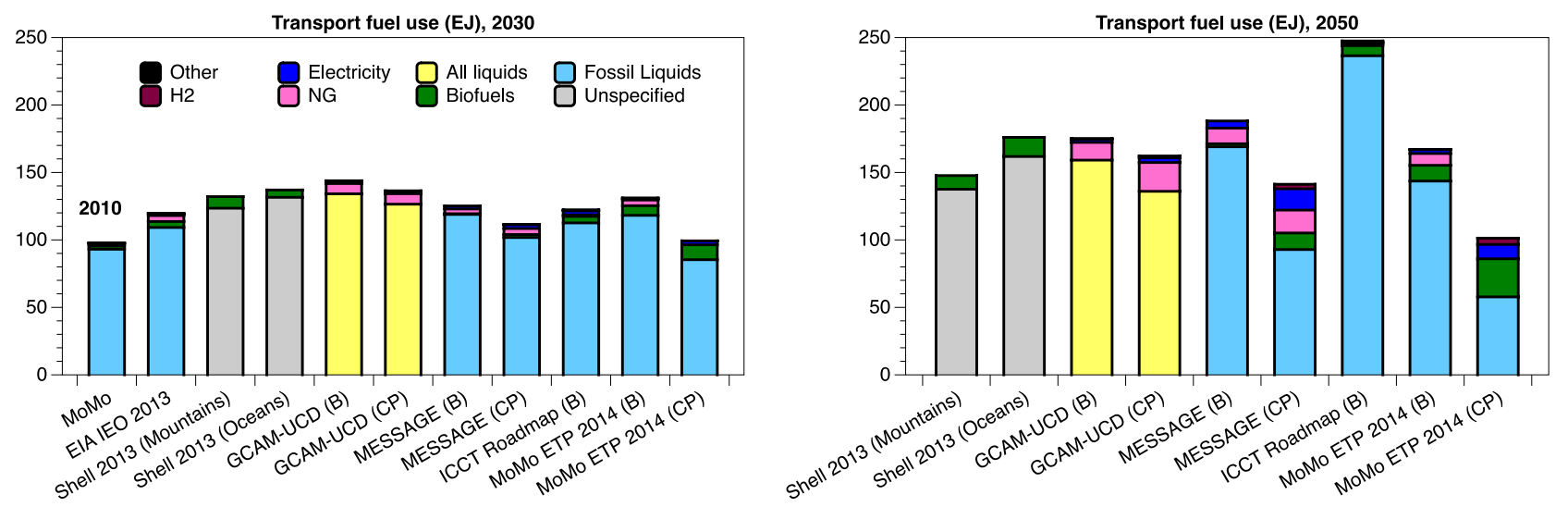

Notes: (a) Energy expressed in lower heating value (LHV) terms. (b) Does not include energy consumed during upstream extraction and conversion. 
Figure S 6. Per capita vehicle ownership (veh/1000 people) globally and in key regions - Baseline (black) and Policy (red) Scenarios (2010-2050)

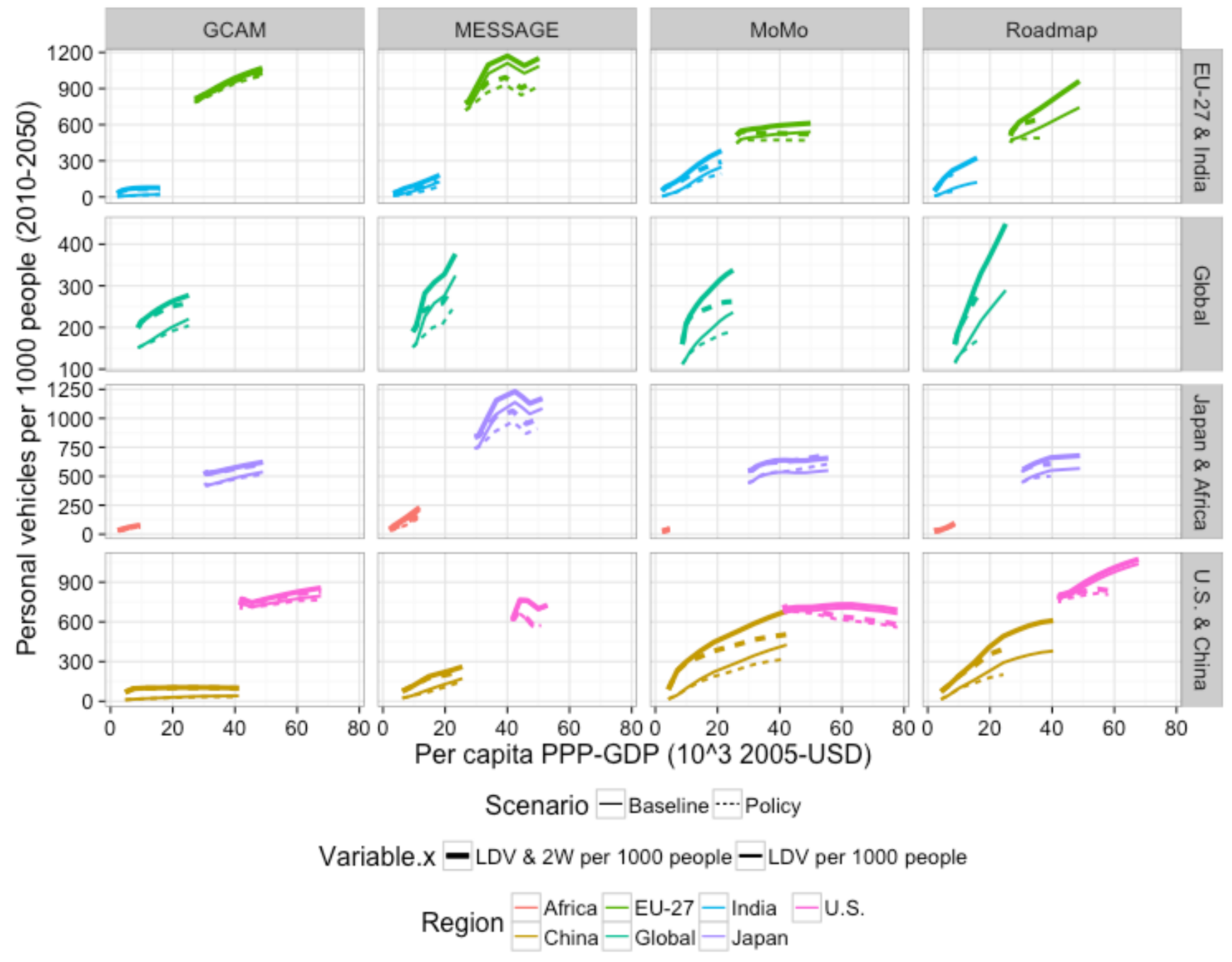


Figure S 7. Projections of annual passenger mobility growth across the Models - Baseline Scenario.

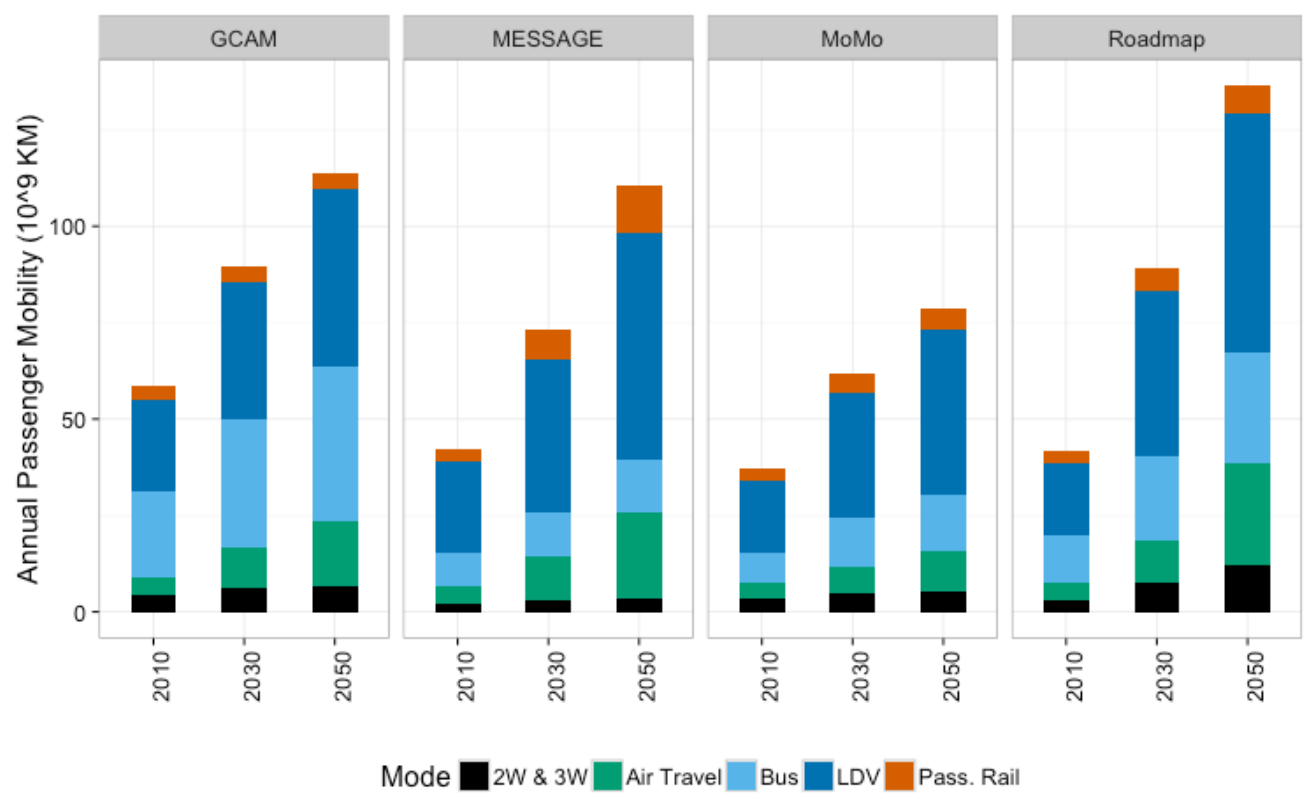

Figure S 8. Global stock of LDVs (cars and light trucks) and two-wheelers - Baseline Scenario (2010-2050)

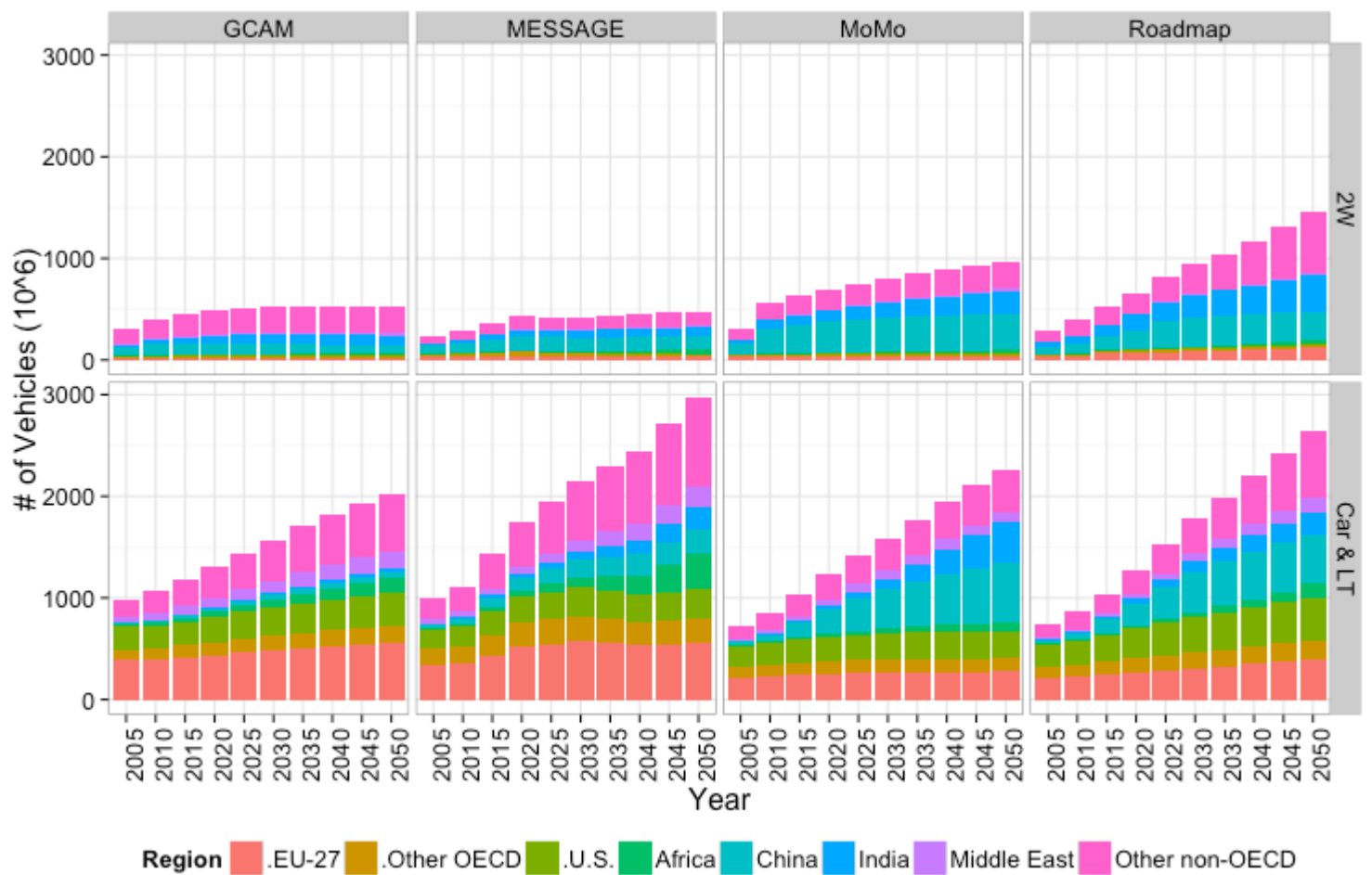


Figure S 9. Per capita mobility in Baseline and Climate Policy scenarios

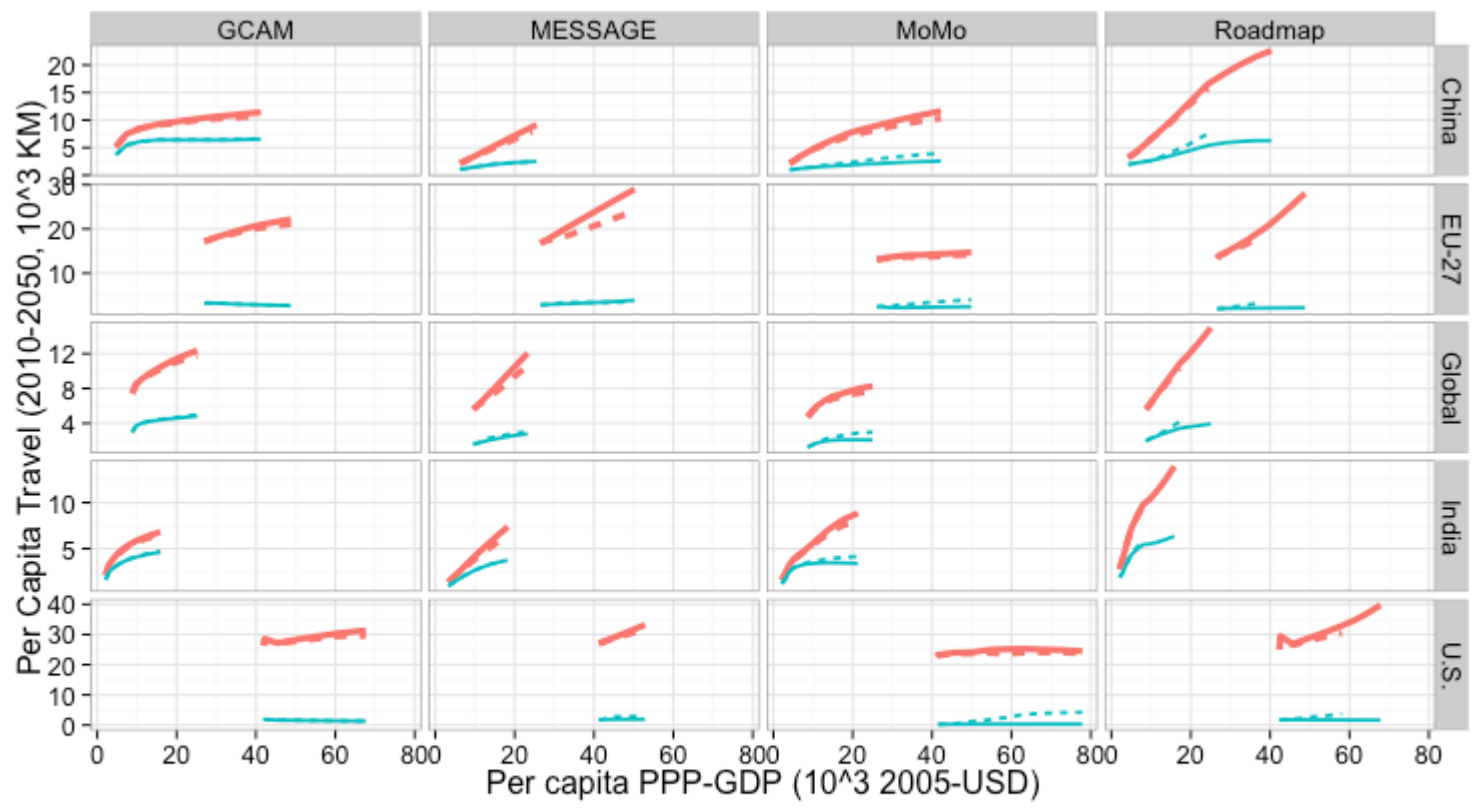

$$
\begin{gathered}
\text { Variable.x }-\begin{array}{l}
\text { Per capita Travel } \\
\text { (All Modes) }
\end{array} \\
\text { Scenario }- \text { Baseline } \cdots \text { Policy } \\
\text { (Public Modes) }
\end{gathered}
$$


Figure S 10. Stock of LDVs (car \& light truck) and two-wheelers in Baseline and Climate Policy scenarios.

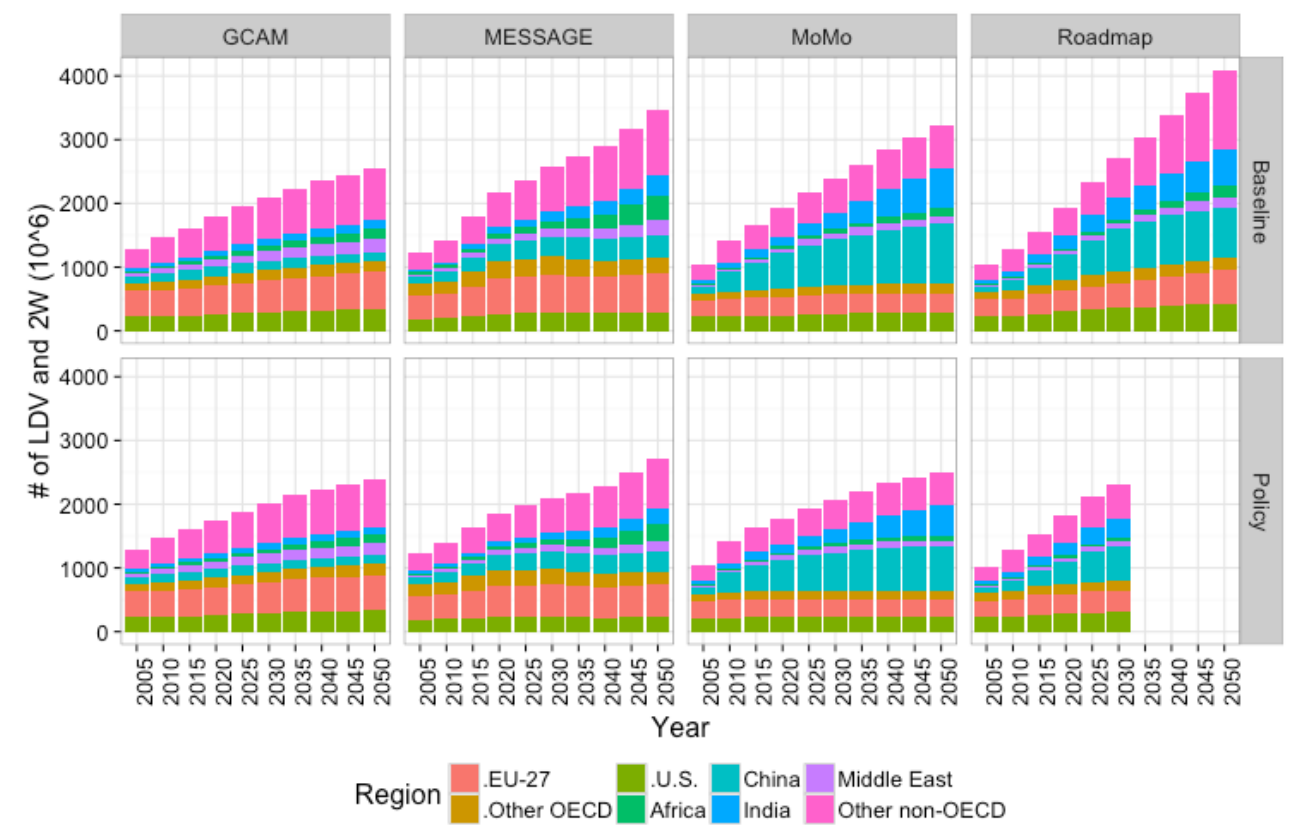

Figure S 11. Average energy intensity of LDVs (car and light truck) (MJ/VKT) in Baseline and Climate Policy scenarios

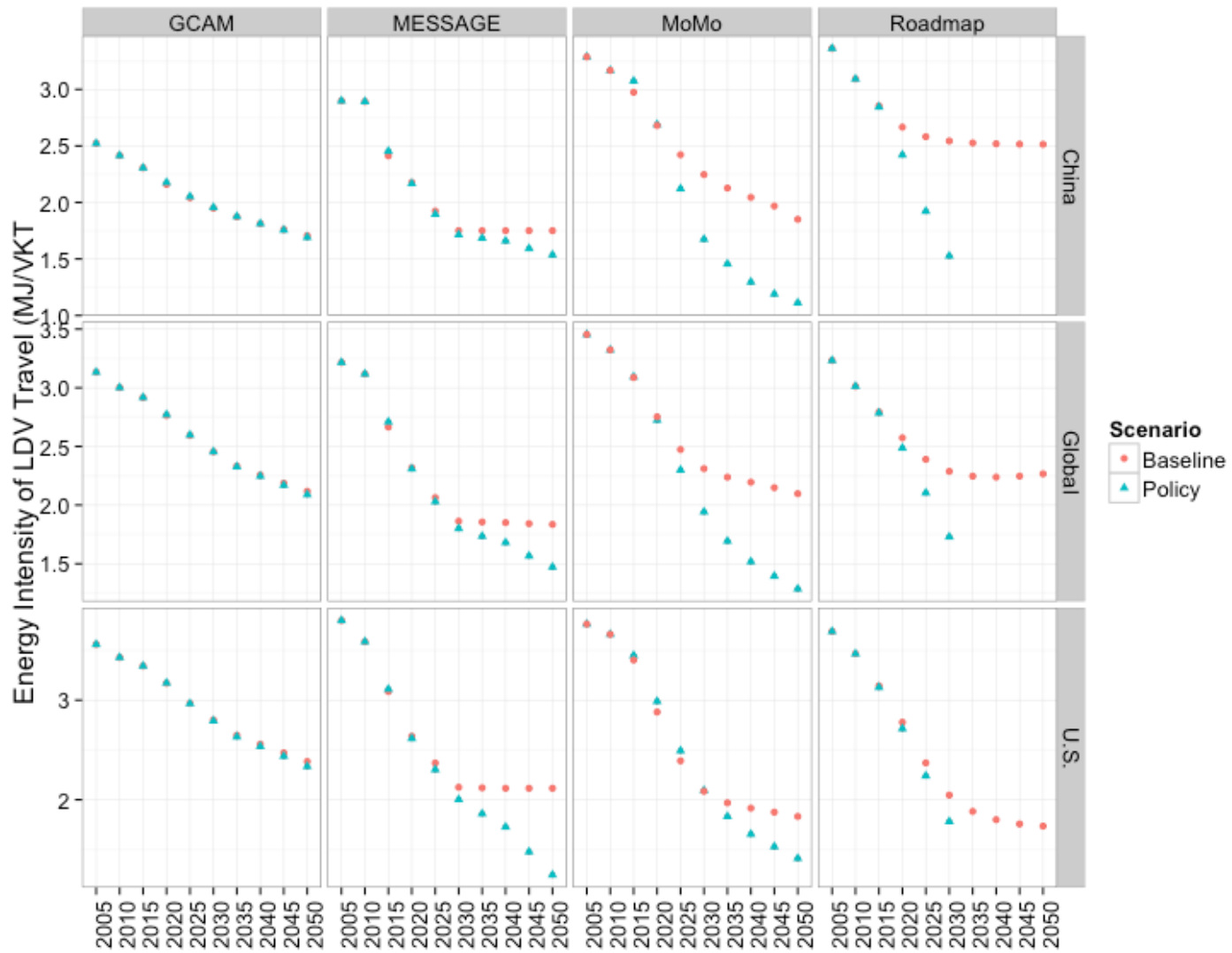




\section{SI A. Methods for decomposition analysis}

$\mathrm{CO}_{2}$ emissions from passenger transportation sector in any given year may be represented by the following Kaya relationship:

$$
\begin{gathered}
C=\sum_{i} P K T p c * \frac{P K T p c_{i}}{P K T p c} * \frac{V K T p c_{i}}{P K T p c_{i}} * \frac{M J_{i}}{V K T_{i}} * \frac{g C O 2_{i}}{M J_{i}} * \text { Pop } \\
C=\sum_{i} P K T p c * S_{i} *\left(1 / L F_{i}\right) * E I_{i} * C I_{i} * P o p
\end{gathered}
$$

where

i : Passenger modes - 2W, 3W, Car \& LT, Bus, Passenger Rail and Air.

PKTpc : Per capita travel in the region

$\mathrm{S}$ : Share of a mode $\mathrm{i}$ in total travel demand (PKT)

LF : Load or occupancy factor of mode $\mathrm{i}$

EI : Average energy intensity of a mode in terms of MJ/VKT

CI : Average carbon intensity (tank-to-wheel) of the fuel

Thus there are six different elements that play a role in determining the $\mathrm{CO} 2$ from transportation, that are separated using the decomposition analysis. The change in $\mathrm{CO}_{2}$ emissions $(\Delta \mathrm{C})$ between the baseline scenario and a carbon policy scenario may be computed as follows:

$$
\Delta C=C_{1}-C_{2}
$$

Where $\mathrm{C}_{1}$ and $\mathrm{C}_{2}$ could refers to annual emissions under two alternative scenarios - baseline and carbon policy scenario.

The above equation may be decomposed in the following terms

$$
\Delta C=\Delta C_{P K T p c}+\Delta C_{S}+\Delta C_{L F}+\Delta C_{E I}+\Delta C_{C I}+\Delta C_{\text {Pop }}+\Delta C_{\text {resid }}
$$

where the terms on the RHS represent the effect of each of the drivers on reductions in carbon emissions (travel reductions, mode shifts, increased vehicle occupancy factors, technological improvements, decarbonization, and population changes).

The following points may be noted about the above equation:

(a) $\Delta \mathrm{C}_{\text {resid }}$ refers to the residual of decomposition analysis. In an ideal decomposition, the residual term is zero. We chose the Divisia method to minimize residuals.

(b) $\Delta \mathrm{C}_{\mathrm{Pop}}$ refers to the delta effect of population in any given year/region assumed by the various models.

(c) $\Delta \mathrm{C}_{\mathrm{EI}}$ captures the joint effect of both technological improvement of individual technologies, as well as differences in relative shares of these technologies (structural differences). The same is true for $\Delta \mathrm{C}_{\mathrm{CI}}$ 
Based on the above equation, the decomposition formula for a logarithmic mean weight Divisia method (LDM) for one of the terms (e.g., $\Delta \mathrm{C}_{\mathrm{PKTpc}}$ ) is given below:

$$
\Delta C_{P K T p c}=\left(\frac{C_{1}-C_{2}}{\ln \left(C_{1} / C_{2}\right)}\right) * \ln \left(\frac{P K T p c_{1}}{P K T p c_{2}}\right)
$$

For a mode-specific term (mode shift effects on carbon emissions):

$$
\Delta C_{S}=\sum_{i} \frac{C_{i 1}-C_{i 2}}{\ln \left(C_{i 1} / C_{i 2}\right)} * \ln \left(\frac{S_{i 1}}{S_{i 2}}\right)
$$

Other terms are similarly calculated. 


\section{Detailed Assessment of Global Transport-Energy Models' Structures and Projections}

Sonia Yeh ${ }^{1,2^{*}}$, Gouri Shankar Mishra ${ }^{1,3}$, Lew Fulton ${ }^{1}$, Page Kyle ${ }^{4}$, David L. McCollum ${ }^{5,6}$, Joshua Miller ${ }^{7}$, Pierpaolo Cazzola ${ }^{8}$, Jacob Teter ${ }^{8}$

${ }^{1}$ Institute of Transportation Studies, University of California, Davis, USA.

${ }^{2}$ Department of Energy and Environment, Chalmers University of Technology, Sweden

${ }^{3}$ Precourt Energy Efficiency Center, Stanford University, USA

${ }^{4}$ Joint Global Change Research Institute, Pacific Northwest National Laboratory, USA.

${ }^{5}$ Energy Program, International Institute for Applied Systems Analysis, Austria.

${ }^{6}$ Howard H. Baker Jr. Center for Public Policy, University of Tennessee, USA.

${ }^{7}$ International Council on Clean Transportation, USA.

${ }^{8}$ International Energy Agency, France

\section{Highlights}

- We compare major global transportation models with considerable technology details to 2050

- There are significant differences in the base-year data and key parameters for future projections

- Main GHG mitigation differs for economics IA models vs transport-only expert models

- Significant EV gaps between policy targets and model trajectories to $2{ }^{\circ} \mathrm{C}$ target

- We offer suggestions on access to data, model improvements, and future comparisons

\footnotetext{
* Corresponding author: sonia.yeh@chalmers.se; Department of Energy and Environment, Chalmers University of Technology, Sweden.
} 